\title{
Computational Fluid Dynamics Investigation of Buoyancy Driven Flow Between Circular Body and Wavy Enclosure Filled with Nanofluid/Porous Medium
}

\author{
Hasan S. Majdi ${ }^{*}$, Ammar Abdulkadhim², Azher M. Abed $^{2}$ \\ ${ }^{1}$ Department of Chemical Engineering and Petroleum Industries, Al-Mustaqbal University College, Babylon 51001, Iraq \\ ${ }^{2}$ Air Conditioning and Refrigeration Techniques Engineering Department, Al-Mustaqbal University College, Babylon 51001, \\ Iraq
}

Corresponding Author Email: AmmarAbdulkadhim@mustaqbal-college.edu.iq

https://doi.org/10.18280/ijht.380216

Received: 22 December 2019

Accepted: 14 May 2020

\section{Keywords:}

natural convection, wavy enclosure, nanofluid, porous, undulation number, position, Rayleigh number

\begin{abstract}
The present work demonstrates the natural convection of two layers filled the space between inner circular cylinder located within wavy enclosure using finite element scheme. The right layer is filled with Ag nano-fluid while the left layer is filled saturated porous media and the same nanofluid. The governing equations of fluid flow and heat transfer (mass, energy and momentum of the fluid) have been formulated in dimensionless form with related initial and boundary conditions the numerical solution include the subdividing the fluid flow domain to two sets of transport equations. The Darcy-Brinkman model was considered for modeling porous media with nano-fluid. The considered dimensionless parameters are Rayleigh number (106 $\geq \mathrm{Ra} \geq 103)$, Darcy number $(10-1 \geq \mathrm{Da} \geq 10-5)$, cylinder's radius $(0.4 \geq R \geq 0.2)$, circular cylinder vertical position $(+0.2 \geq \delta \geq-0.2)$, the number of undulation $(3 \geq N \geq 0)$ and nano-particle volume fraction $(0.1 \geq \varphi \geq 0)$. The nanofluid is combining of $\mathrm{Ag}$ solid particle and water as a main fluid. The results were presented according to the stream-lines, isotherms, local and the mean of Nusselt number. The results have demonstrated the increasing in the value of the Rayleigh and Darcy numbers as well as nanofluid volume fraction enhances both fluid flow strength and average of heat transfer. It has been concluded that when the number of undulations $\mathrm{N}=1$ gives better heat transfers enhancement. It is recommended that for better heat transfer average to move the internal circular cylinder with radius $(\mathrm{R}=0.2)$ vertically downward $(\delta=-0.2)$ with undulations' number $(\mathrm{N}=1)$.
\end{abstract}

\section{INTRODUCTION}

Natural convection heat transfer in different porous enclosure shapes like square, rectangle, triangle, oblique, trapezoidal, wavy and others shapes took a great deal of interest because of its applications in industry and engineering like nuclear processing, air conditioning in rooms, float production [1-21]. The natural convection heat transfer in enclosures filling partly with fluid and partly with saturated porous media with the same fluid had been studied in open literature as a result of its wide range of applications like fuel cell, production of crude oil, geothermal systems.

The thermal fluids have an important function of the enhancement of the heat transfer. However, the conventional fluids like mixture of ethylene glycol, oil and water has law thermal conductivity which makes a serious problem in augmentation of heat transfer. In order to overcome this limitation, there was a strong motivation towards adding of solid particle in to the main fluid to form what we called nanofluid [22]. Various researchers studied the nanofluid filling enclosures. For example; Kahwaji and Ali [23] investigated numerically by utilizing alternating direction implicit technique to simulate the natural convection between square cylinder within a square enclosure. The space filling with copper-water nano-fluid. The results demonstrated an increase in the numbers of Rayleigh and fraction volume of
Nanofluid augmented the numbers of Nusselt leading to enhance the heat transfer. Selimefendigil et al. [24] examined numerically entropy generation and natural convections in nano-fluid trapezoidal enclosure including the impact of the magnetic fields. They have concluded that heat transfer augmentation rates with nano-fluids ranging from 0.1 to 0.12 aren't influenced with the existence of magnetic fields.

The internal body placed inside various shapes of enclosure has been researched by numerous researchers. The effect of internal body size on various shapes of enclosures were investigated by Angeli et al. [25] and Xu et al. [26]. Angeli et al. [25] researched numerically utilizing CFD commercial code Fluent the effect of changing the cylinder that is placed in a square enclosure filling with air. Four different numeric magnitudes of cylinder diameter were taken $(0.2,0.4,0.6$ and $0.8)$. A correlation of average Nusselt number as a function of both Rayleigh and diameter to side ratio had been developed with an accuracy better than $\pm 10 \%$. Xu et al. [26] examined in a numerical way the natural convection between horizontal triangular cylinder placed inside cylindrical enclosure filling with air utilizing finite volume technique. They studied the effect of internal body diameter and its inclination angle under various four numbers of Rayleigh's magnitudes. They proposed a correlation based on curve fitting to average Nusselt number as a Rayleigh number function under a variety of values for the radius ratio for laminar flow. They have 
reached the conclusion that the inner triangular cylinder's inclination angle had no impacts on average Nusselt number when radius ratio remained unchanged. Other researchers researched the impact of the change of the internal body location vertically [27-36], horizontally [37].

Kim et al. [27], Hussain and Hussein [28] researched numerically the natural transfer of heat convection between cylinder which is placed in square enclosure filled by air. The difference between these two studies is that Kim et al. [27] kept the cylinder under isotherm hot temperature while Hussain and Hussein [28] applied constant heat flux to the cylinder. They examined the impact of Rayleigh's number and different vertical location on the Nusselt's number and the results have indicated that Nusselt number augmented with increasing Rayleigh's number in case of a vertical movement of the cylinder upward or downward. Yoon et al. [29] studied the internal cylinder vertical position placed inside the square enclosure. Their obtained results indicated that, under the transient region, the free convection showed in accordance with the location of the inner circular cylinder, a single and multiple frequencies periodic patterns. Another investigation for Hussain and Hussein [30] examined the mixed heat transfer convection between internal conductive cylinder in a square enclosure at a variety of the vertical positions. They explained that the value of the Reynolds, Richardson numbers and the rotating cylinder positions has a significant influence on fluid flow field and distribution of temperature like in augmentation of convection heat transfer in square cavity Park et al. [31] have published a research comparing the effect of two internal cylinders and compared them with the single cylinder placed within a square enclosure utilizing the absorbed boundary technique based upon the method of finite volume. It has been concluded that two cylinder give better amount of heat transfer than that of a single cylinder.

Park et al. [32] investigated the position of two pairs of internal cylinder at various vertical positions for various numbers of Rayleigh using immersed boundary approach which is based on the approach of the finite volume. They discovered that the profile of the Nusselt number is symmetrical at low Rayleigh numbers while this symmetry is broken at high values of Rayleligh number because of increasing the convection forces. It is also obtained that at high Rayleigh numbers for a certain value of vertical location, there will be bifurcation from steady into transient conditions. Majdi et al. [34] investigated utilizing the method of finite element on natural convection between cylinder placed in nanofluid parallelogramic enclosure under various vertical position. The influence of Rayleigh number, nanofluid loading, vertical location and inclination angle of enclosure on heat transfer and fluid flow were illustrated in full-details. Results have indicated that for better heat transfer enhancements, the recommendation is moving the inner circular cylinder with an inclination angle equals to 30 . Another investigation using Lattice Boltzmann had been applied for natural convection around horizontal hot elliptical cylinder placed in a square enclosure for various vertical locations [35]. The results displayed that increasing of Rayleigh's number, yields in an enhancement in average Nusselt number and its minimal magnitude will be farther from the top of elliptical inner body when the Rayleigh number goes up. Very recently, the effect of four internal cylinder vertical and horizontal distance had been reported by Mun et al. [36] using the immersed boundary layer approach. The results have shown that transition from the steady conditions into the unsteady take place relatively at high values of Rayleigh's number. Abdelmalek et al. [38] studied the natural convection heat transfer between wavy enclosure located within square enclosure. It is obtained by increasing the inner body number of undulations, there is increasing in heat transfer rate.

Enhancing the heat transfer could be done either by nanofluid or by corrugated enclosure walls to form what we call corrugated or wavy enclosure [39]. There are many publications for wavy enclosures [40-52]. Cho et al. [41] demonstrated numerically natural convection in the wavy enclosure filling with nano-fluid consists from $\mathrm{Al}_{2} \mathrm{O}_{3}$. They have reached a conclusion that the increase of nano-fluid loading, Rayleigh number and tuning wavy surface of enclosure can augment the transfer of heat. Esmaeilpour and Abdollah-zadeh [42] have researched the effect of numbers' of Grashof and copper-water nanofluid volume fraction on the generation of entropy and natural convection of four different shapes of wavy enclosures (Simple, In-In, Out-Out, and InOut) by utilizing the method of finite volume. The researchers found out that the pattern of Out-Out has the maximal magnitude of Nusselt number. Beside that they obtained that the pattern of In-In has the minimal value of generation of the average Entropy. Cho et al. [43] have proposed a numerical study of the natural convection and production of entropy in a wavy inclined enclosure filling with nanofluid. It is concluded that increasing of volume fraction lead to enhancement in heat transfer and reduces total generation of entropy. Shirvan et al. [44] researched numerically the impact of the wavy surface of a cosine corrugated nanofluid enclosure on natural convection. It has been discovered that increasing amplitudes and wavelengths of the wavy walls lead to reduces both heat transfer and fluid flow intensity. Boulahia et al. [45] have researched the natural heat transfer convection between 2 internal cylinders which have been placed in a wavy enclosure filled by nano-fluid by finite volume approach including the impact of wavy amplitude and undulation number, the number of Rayleigh and volume fraction. The results demonstrated that decreasing the wavy amplitude and increasing the undulation number, the number of Rayleigh and volume fraction contributes in enhancing the heat transfer.

Elshehabey et al. [53] studied the MHD in partial open wavy enclosure filled with ferrofluid using finite element scheme. The results indicate the Boussinseq parameter had posatve impact on the movement of the ferrofluid.

Nabavizadeh et al. [46] have proposed a numerical study for convection of the natural heat transfer between corrugated internal cylinder placed inside wavy enclosure filling with air utilizing thermal lattice Boltzmann technique. Results have demonstrated that increasing the amplitudes, the number of the Nusselts will augment. While undulation numbers might cause an increase or decrease in the number of the Nusselts. However, there were negligible impacts of rotation on the heat transfer. Also another investigation for the impact of magnetic field on natural convection between corrugated internal body placed within the square enclosure filling with multiple layers of the nano-fluid with porous media saturated by similar nanofluid was demonstrated by Sheikholeslami et al. [47]. They obtained that the thermal boundary layer gets thinner with an improvement in radiation parameter and the Rayleigh's number. Sheikholeslami [48] used the method of control volume finite element for investigating the effects of radiation and magnetic field on the natural convection between annulus corrugated bodies filling with multilayer of nanofluid and porous media. He obtained that increasing the value of 
radiation parameter leads to enhancing the Nusselt number Alsabery et al. [50] have researched mixing convection and generating entropy between internal rotating cylinder placed inside wavy enclosure heated from below and filled by porous media. They found that improvements in porosity of the medium lead to enhancing the convective flow and reducing in the Bejan number. Increasing the oscillation number results in reducing both the convection flow and generating of the entropy. Alsabery et al. [51] extended their previous study presented by Alsabery et al. [50] for wavy enclosure filling with the nano-fluid. They obtained that undulating the walls decreases the average Nusselt number at $\mathrm{Ra}=105$ and its effect is for still cylinder while the effect of undulations for rotating cylinder is negligible. Farooq et al. [52] have researched the mixed convection between internal corrugated cylinder placed in outer rotating cylinder filling with nano-fluid for various internal corrugation numbers. They have concluded that average Nusselt number decreases with the increase of the Reynolds number and corrugations number. Recently, Hussain and Rahomey [54] studied the natural convection between various internal cylinder bodies like circular, square, triangular and elliptical placed within a square enclosure filling by nanofluid and porous media saturated by the same nano-fluid. Results have shown that is better in heat transfer rate.

Recently, Mebarek [55] examined different types of base fluid like oil, ethylene glycol, water with $\mathrm{TiO}_{2}$ nanofluid along with discrete heating using finite volume method. The results indicated that nanofluid and Rayleigh number enhances the heat transfer rate. Mahanthesh et al. [56] demonstrated the exponential spacing and heat source impact on the fluid flow of nanofluid in elongated disk radially considering Lorentz and carioles forces. Mebarek and Bessaih [57] studied the natural convection in annulus cylinders located vertically with partial heating. The results indicate that the length of the heaters effect on the heat transfer rate significantly. Gourari et al. [58] examine free convection within two inclined cylinders for various inclination angle $(0,45,90)$. The results indicate that 90 degree is the best inclination angle for heat transfer characteristics. Parveen and Mahapatra [59] examined the natural convection, entropy generation along with the double diffusive in square nanofluid enclosure with wavy walled in its top wall. The results indicate that increasing the buoyancy ratio and Hartmann number decreases the heat transfer while the nanofluid and Rayleigh number augment it. Dogonchi et al. [60] examine the magnetic field in irregularly wavy heated enclosure filled with nanofluid using control volume finite element scheme

From previous literature review, it can be seen that most of the previous investigation contain only layer nanofluid alone filled the enclosure or only porous media and there is limitation in the multi-layer filled the enclosure. Beside that the complex enclosure shapes like the wavy was also less than the simple shapes like square, rectangle, triangle and other simple shapes. Thus the major novelty of the present work is the mixing of nanofluid and saturated porous medium filled one of the complex shapes in the numerical modelling which is the wavy enclosure contain inner circular cylinder. Therefore, this research will be the first investigation attempt to study this issue. In this research, the natural convection heat transfer will be studied numerically utilizing Galerkin Finite Element approach for different dimensionless parameters like numbers of Rayleigh $(106 \geq \mathrm{Ra} \geq 103)$ and Darcy $(10-1 \geq \mathrm{Da} \geq 10$ $5)$, The internal cylinder vertical position $(+0.2 \geq \delta \geq-0.2)$, radius of internal cylinder $(0.4 \geq R \geq 0.2)$, Number of sinusoidal number of enclosure $(3 \geq \mathrm{N} \geq 0)$ and nano-particle fraction of the volume $(0.1 \geq \varphi \geq 0)$.

\section{METHODOLOGY}

Two-dimensional of the computational domain which has been considered in the present work is presented in Figure 1. It consists of a circular internal cylinder placed within wavy vertical walled enclosure.

$$
Y=\lambda \sin (N y) \pm \check{Y}
$$

$\mathrm{N}$ represents the number of the sinusoidal waves, $\breve{\mathrm{Y}}$ represents the distance between the original and sinusoidal wall locations, and $\lambda$ represents the sinusoidal amplitude.

Uniform isothermal hot temperature is implemented for internal cylinder whereas the 2 horizontal walls are adiabatic and wavy walls have been maintained at isothermal cold temperatures. The enclosure is divided by a permeable interface to two vertically placed layers. The working fluid in wavy enclosure is made up of two layers: the first (i.e. the right) one is a nano-fluid and the second (i.e. the left) layer is filled by saturated porous media with same nano-fluid. The problem is modelled mathematically according to the following assumptions:

(1) The fluid flow is projected an incompressible, laminar under the conditions of the steady state.

(2) Internal heat generation resulting from the Darcy dissipation or viscous dissipation is neglected and the radiation effect is insignificant.

(3) The nano-particle is of a uniform in size and spherical shape. The thermo-physical characteristics are constant except for the body force density.

(4) No slip takes place between liquid and nano-particles concerning velocity and temperature.

(5) A thermal equilibrium has been taken under consideration between the nano-fluid and the porous media.

The thermo-physical properties of the pure fluid and the $\mathrm{Ag}$ nano-fluid have been listed below in Table1. The governing dimensionless parameters which are Rayleigh's number $\left(10^{6} \geq \mathrm{Ra} \geq 10^{3}\right)$, Darcy's number $\left(10^{-1} \geq \mathrm{Da} \geq 10^{-5}\right)$, the vertical location, wavy wall undulation number $(3 \geq N \geq 0)$ and nanoparticle volume fraction $(0.1 \geq \varphi \geq 0)$.

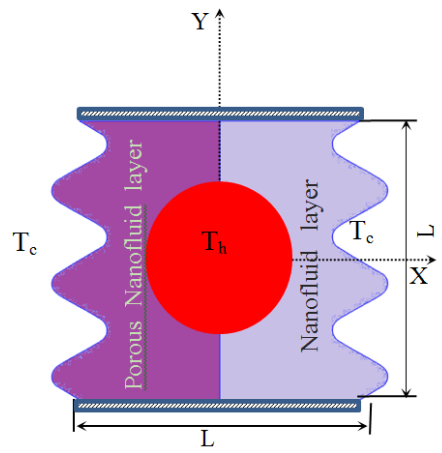

Figure 1. Schematic diagram of the problem

In this study the double domain method has been utilized for describing the mathematical model. The governing formulas have been applied and separated for every one of the 
domains, which are combined with proper conditions of the boundary along the permeable surfaces. Darcy-Brinkman's method has been utilized for signifying the convection entire porous domain. This method has been simplified for coupling of the momentum equation between nano-fluid domain and porous domain. The governing equations for the nano-fluid domain in the dimensional form are $[54,61]$ :

Continuity:

$$
\frac{\partial u_{n a}}{\partial x}+\frac{\partial v_{n a}}{\partial y}=0
$$

X-momentum:

$$
\begin{aligned}
\rho_{\text {na }}\left(u_{\text {na }} \frac{\partial u_{n a}}{\partial x}+v_{n a} \frac{\partial u_{n a}}{\partial y}\right) \\
=-\frac{\partial p}{\partial x}+\mu_{n a}\left(\frac{\partial^{2} u_{n a}}{\partial x^{2}}+\frac{\partial^{2} u_{n a}}{\partial y^{2}}\right)
\end{aligned}
$$

Y-momentum:

$$
\begin{aligned}
\rho_{\mathrm{na}} & \left(\mathrm{u}_{\mathrm{na}} \frac{\partial \mathrm{v}_{\mathrm{na}}}{\partial \mathrm{x}}+\mathrm{v}_{\mathrm{na}} \frac{\partial \mathrm{v}_{\mathrm{na}}}{\partial \mathrm{y}}\right) \\
& =-\frac{\partial \mathrm{p}}{\partial \mathrm{y}}+\mu_{\mathrm{na}}\left(\frac{\partial^{2} \mathrm{v}_{\mathrm{na}}}{\partial \mathrm{x}^{2}}+\frac{\partial^{2} \mathrm{v}_{\mathrm{na}}}{\partial \mathrm{y}^{2}}\right) \\
& +\beta_{\mathrm{na}} \rho_{\mathrm{na}} \mathrm{g}\left(\mathrm{T}_{\mathrm{h}}-\mathrm{T}_{\mathrm{c}}\right)
\end{aligned}
$$

Energy

$$
\mathrm{u}_{\mathrm{na}} \frac{\partial \mathrm{T}_{\mathrm{na}}}{\partial \mathrm{x}}+\mathrm{v}_{\mathrm{na}} \frac{\partial \mathrm{T}_{\mathrm{na}}}{\partial \mathrm{y}}=\left(\frac{\partial^{2} \mathrm{~T}_{\mathrm{na}}}{\partial \mathrm{x}^{2}}+\frac{\partial^{2} \mathrm{~T}_{\mathrm{na}}}{\partial \mathrm{y}^{2}}\right)
$$

The 2-D governing equations for porous media partitions are:

Continuity:

$$
\frac{\partial \mathrm{u}_{\mathrm{po}}}{\partial \mathrm{x}}+\frac{\partial \mathrm{v}_{\mathrm{po}}}{\partial \mathrm{y}}=0
$$

X-momentum:

$$
\begin{aligned}
\rho_{\mathrm{na}}\left(\mathrm{u}_{\mathrm{po}} \frac{\partial \mathrm{u}_{\mathrm{po}}}{\partial \mathrm{x}}+\right. & \left.\mathrm{v}_{\mathrm{po}} \frac{\partial \mathrm{u}_{\mathrm{po}}}{\partial \mathrm{y}}\right) \\
& =-\varepsilon^{2} \frac{\partial \mathrm{p}}{\partial \mathrm{x}} \\
& +\epsilon \mu_{\mathrm{na}}\left(\frac{\partial^{2} \mathrm{u}_{\mathrm{po}}}{\partial \mathrm{x}^{2}}+\frac{\partial^{2} \mathrm{u}_{\mathrm{po}}}{\partial \mathrm{y}^{2}}\right) \\
& -\epsilon^{2} \frac{\mu_{\mathrm{na}}}{\mathrm{k}} \mathrm{u}_{\mathrm{po}}
\end{aligned}
$$

Y-momentum:

$$
\begin{aligned}
\rho_{\text {na }}\left(\mathrm{u}_{\mathrm{po}} \frac{\partial \mathrm{v}_{\mathrm{po}}}{\partial \mathrm{x}}+\right. & \left.\mathrm{v}_{\mathrm{po}} \frac{\partial \mathrm{v}_{\mathrm{po}}}{\partial \mathrm{y}}\right) \\
& =-\varepsilon^{2} \frac{\partial \mathrm{p}}{\partial \mathrm{y}} \\
& +\varepsilon \mu_{\mathrm{na}}\left(\frac{\partial^{2} \mathrm{v}_{\mathrm{po}}}{\partial \mathrm{x}^{2}}+\frac{\partial^{2} \mathrm{v}_{\mathrm{po}}}{\partial \mathrm{y}^{2}}\right) \\
& -\varepsilon^{2} \frac{\mu_{\mathrm{na}}}{\mathrm{k}} \mathrm{v}_{\mathrm{po}}+\beta_{\mathrm{na}} \rho_{\mathrm{na}} \mathrm{g}\left(\mathrm{T}-\mathrm{T}_{\mathrm{c}}\right)
\end{aligned}
$$

Energy

$$
\mathrm{u}_{\mathrm{po}} \frac{\partial \mathrm{T}_{\mathrm{po}}}{\partial \mathrm{x}}+\mathrm{v}_{\mathrm{po}} \frac{\partial \mathrm{T}_{\mathrm{po}}}{\partial \mathrm{y}}=\alpha_{\mathrm{eff}}\left(\frac{\partial^{2} \mathrm{~T}_{\mathrm{po}}}{\partial \mathrm{x}^{2}}+\frac{\partial^{2} \mathrm{~T}_{\mathrm{po}}}{\partial \mathrm{y}^{2}}\right)
$$

$\rho$ represents density, $\mu$ represents the dynamic viscosity, $\alpha$ represents the thermal diffusivity, $K$ represents the permeability, $\varepsilon$ represents the porosity, $\beta$ represents the coefficient of the thermal expansion. na, po, fl are subscripts signify for nano-fluid, porous media and pure fluid. Through the assumption that the equation for the stream function $(\mathrm{u}=$ $\left.\frac{\partial \psi}{\partial \mathrm{y}}\right),\left(\mathrm{v}=-\frac{\partial \Psi}{\partial \mathrm{x}}\right)$ and vorticity $\left(\omega=\frac{\partial \mathrm{v}}{\partial \mathrm{x}}-\frac{\partial \mathrm{u}}{\partial \mathrm{y}}\right)$ and presenting the dimensionless parameters below:

$$
\begin{aligned}
& \mathrm{X}=\frac{\mathrm{x}}{\mathrm{L}} ; \mathrm{Y}=\frac{\mathrm{y}}{\mathrm{L}} ; \mathrm{V}=\frac{\mathrm{vL}}{\alpha_{\mathrm{fl}}} ; \mathrm{U}=\frac{\mathrm{uL}}{\alpha_{\mathrm{fl}}} ; \mathrm{P}=\frac{\mathrm{pL}^{2}}{\rho_{\mathrm{na}} \alpha_{\mathrm{f}}^{2}} ; \mathrm{Da}=\frac{\mathrm{k}_{\mathrm{fl}}}{\mathrm{L}^{2}} ; \theta= \\
& \frac{\mathrm{T}-\mathrm{T}_{\mathrm{c}}}{\mathrm{T}_{\mathrm{h}}-\mathrm{T}_{\mathrm{c}}} \\
& \mathrm{Ra}=\frac{\mathrm{g} \beta_{\mathrm{fl}}\left(\mathrm{T}_{\mathrm{h}}-\mathrm{T}_{\mathrm{c}}\right) \mathrm{L}^{3}}{\mathrm{v}_{\mathrm{fl}} \alpha_{\mathrm{fl}}}, \operatorname{Pr}=\frac{\mathrm{v}_{\mathrm{fl}}}{\alpha_{\mathrm{fl}}}, \Psi=\frac{\Psi}{\alpha_{\mathrm{fl}}}, \Omega=\frac{\omega \mathrm{L}^{2}}{\alpha_{\mathrm{fl}}}
\end{aligned}
$$

The physical characteristics of the nanofluid could be expressed as follows:

$$
\begin{gathered}
\rho_{\mathrm{na}}=(1-\varphi) \rho_{\mathrm{fl}}+\varphi \rho_{\mathrm{po}} \\
(\rho \beta)_{\mathrm{na}}=(1-\varphi)(\rho \beta)_{\mathrm{fl}}+\varphi(\rho \beta)_{\mathrm{po}} \\
\alpha_{\mathrm{na}}=\frac{\mathrm{K}_{\mathrm{na}}}{\left(\rho \mathrm{c}_{\mathrm{p}}\right)_{\mathrm{na}}} \\
\alpha_{\mathrm{eff}}=\frac{\mathrm{K}_{\mathrm{eff}}}{\left(\rho \mathrm{c}_{\mathrm{p}}\right)_{\mathrm{n}}} \\
\mathrm{K}_{\mathrm{eff}}=(1-\varepsilon) \mathrm{K}_{\mathrm{s}}+\varepsilon \mathrm{K}_{\mathrm{na}} \\
\left(\rho \mathrm{c}_{\mathrm{p}}\right)_{\mathrm{na}}=(1-\varphi)\left(\rho \mathrm{c}_{\mathrm{p}}\right)_{\mathrm{fl}}+\varphi\left(\rho \mathrm{c}_{\mathrm{p}}\right)_{\mathrm{po}}
\end{gathered}
$$

The thermal conductivity and viscosity of nanofluid models have been calculated using Eq. (17-18) which had been used by many researchers like [39, 61-72]:

$$
\begin{gathered}
\mathrm{K}_{\mathrm{na}}=\mathrm{K}_{\mathrm{fl}} \frac{\left(\mathrm{K}_{\mathrm{po}}+2 \mathrm{~K}_{\mathrm{fl}}\right)-2 \varphi\left(\mathrm{K}_{\mathrm{fl}}-\mathrm{K}_{\mathrm{po}}\right)}{\left(\mathrm{K}_{\mathrm{po}}+2 \mathrm{~K}_{\mathrm{fl}}\right)+\varphi\left(\mathrm{K}_{\mathrm{fl}}-\mathrm{K}_{\mathrm{po}}\right)} \\
\mu_{\mathrm{na}}=\frac{\mu_{\mathrm{fl}}}{(1-\varphi)^{2.5}}
\end{gathered}
$$

The dimensionless governing equations take the following form:

Continuity:

$$
\frac{\partial \mathrm{U}_{\mathrm{na}}}{\partial \mathrm{X}}+\frac{\partial \mathrm{V}_{\mathrm{na}}}{\partial \mathrm{Y}}=0
$$

X-momentum:

$$
\begin{aligned}
\mathrm{U}_{\mathrm{na}} \frac{\partial \mathrm{U}_{\mathrm{na}}}{\partial \mathrm{X}}+\mathrm{V}_{\mathrm{na}} \frac{\partial \mathrm{U}_{\mathrm{na}}}{\partial \mathrm{Y}} & \\
= & -\frac{\partial \mathrm{P}}{\partial \mathrm{X}} \\
& +\frac{\operatorname{Pr}}{(1-\varphi)^{2.5}} \frac{\rho_{\mathrm{fl}}}{\rho_{\mathrm{na}}}\left(\frac{\partial^{2} \mathrm{U}_{\mathrm{na}}}{\partial \mathrm{X}^{2}}+\frac{\partial^{2} \mathrm{U}_{\mathrm{na}}}{\partial \mathrm{Y}^{2}}\right)
\end{aligned}
$$


Y-momentum:

$$
\begin{aligned}
\mathrm{U}_{\mathrm{na}} \frac{\partial \mathrm{V}_{\mathrm{n}}}{\partial \mathrm{X}}+\mathrm{V}_{\mathrm{na}} \frac{\partial \mathrm{V}_{\mathrm{na}}}{\partial \mathrm{Y}} & \\
& =-\frac{\partial \mathrm{P}}{\partial \mathrm{Y}} \\
& +\frac{\operatorname{Pr}}{(1-\varphi)^{2.5}} \frac{\rho_{\mathrm{fl}}}{\rho_{\mathrm{na}}}\left(\frac{\partial^{2} \mathrm{~V}_{\mathrm{na}}}{\partial \mathrm{X}^{2}}+\frac{\partial^{2} \mathrm{~V}_{\mathrm{na}}}{\partial \mathrm{Y}^{2}}\right) \\
& +\frac{(\rho \beta)_{\mathrm{na}}}{\rho_{\mathrm{na}} \beta_{\mathrm{fl}}} \operatorname{RaPr} \theta
\end{aligned}
$$

Energy:

$$
\mathrm{U}_{\mathrm{na}} \frac{\partial \theta_{\mathrm{na}}}{\partial \mathrm{X}}+\mathrm{V}_{\mathrm{na}} \frac{\partial \theta_{\mathrm{na}}}{\partial \mathrm{Y}}=\frac{\alpha_{\mathrm{na}}}{\alpha_{\mathrm{fl}}}\left(\frac{\partial^{2} \theta_{\mathrm{n}}}{\partial \mathrm{X}^{2}}+\frac{\partial^{2} \theta_{\mathrm{n}}}{\partial \mathrm{Y}^{2}}\right)
$$

The dimensionless form of the governing formulas for the porous media domain is:

Continuity:

$$
\frac{\partial \mathrm{U}_{\mathrm{po}}}{\partial \mathrm{X}}+\frac{\partial \mathrm{V}_{\mathrm{po}}}{\partial \mathrm{Y}}=0
$$

X-momentum:

$$
\begin{aligned}
\mathrm{U}_{\mathrm{po}} \frac{\partial \mathrm{U}_{\mathrm{po}}}{\partial \mathrm{X}}+\mathrm{V}_{\mathrm{po}} \frac{\partial \mathrm{U}_{\mathrm{po}}}{\partial \mathrm{Y}} & \\
& =-\frac{\partial \mathrm{P}}{\partial \mathrm{X}} \\
& +\frac{\operatorname{Pr}}{(1-\varphi)^{2.5}} \frac{\rho_{\mathrm{fl}}}{\rho_{\mathrm{na}}}\left(\frac{\partial^{2} \mathrm{U}_{\mathrm{po}}}{\partial \mathrm{X}^{2}}\right. \\
& \left.+\frac{\partial^{2} \mathrm{U}_{\mathrm{po}}}{\partial \mathrm{Y}^{2}}\right)-\frac{\operatorname{Pr}}{(1-\varphi)^{2.5}} \frac{\rho_{\mathrm{fl}}}{\rho_{\mathrm{na}}} \frac{\mathrm{U}_{\mathrm{po}}}{\mathrm{Da}}
\end{aligned}
$$

Y-momentum:

$$
\begin{aligned}
\mathrm{U}_{\mathrm{po}} \frac{\partial \mathrm{V}_{\mathrm{po}}}{\partial \mathrm{X}}+\mathrm{V}_{\mathrm{po}} \frac{\partial \mathrm{V}_{\mathrm{po}}}{\partial \mathrm{Y}} & \\
& =-\frac{\partial \mathrm{P}}{\partial \mathrm{Y}} \\
& +\frac{\operatorname{Pr}}{(1-\varphi)^{2.5}} \frac{\rho_{\mathrm{fl}}}{\rho_{\mathrm{na}}}\left(\frac{\partial^{2} \mathrm{~V}_{\mathrm{po}}}{\partial \mathrm{X}^{2}}+\frac{\partial^{2} \mathrm{~V}_{\mathrm{po}}}{\partial \mathrm{Y}^{2}}\right) \\
& -\frac{\operatorname{Pr}}{(1-\varphi)^{2.5}} \frac{\rho_{\mathrm{fl}}}{\rho_{\mathrm{na}}} \frac{\mathrm{V}_{\mathrm{po}}}{\mathrm{Da}} \\
& +\frac{(\rho \beta)_{\mathrm{na}}}{\rho_{\mathrm{na}} \beta_{\mathrm{fl}}} \operatorname{RaPr} \theta
\end{aligned}
$$

Energy:

$$
\mathrm{U}_{\mathrm{po}} \frac{\partial \theta_{\mathrm{po}}}{\partial \mathrm{X}}+\mathrm{V}_{\mathrm{po}} \frac{\partial \theta_{\mathrm{po}}}{\partial \mathrm{Y}}=\frac{\alpha_{\mathrm{na}}}{\alpha_{\mathrm{fl}}}\left(\frac{\partial^{2} \theta_{\mathrm{po}}}{\partial \mathrm{X}^{2}}+\frac{\partial^{2} \theta_{\mathrm{po}}}{\partial \mathrm{Y}^{2}}\right)
$$

The boundary conditions on outside enclosure walls are:

At $\mathrm{X}=0 \mathrm{U}=\mathrm{V}=\Psi=0, \theta=0$ (left side wall),

At $X=1 \mathrm{U}=\mathrm{V}=\Psi=0, \theta=0$ (right side wall)

At $\mathrm{Y}=0 \mathrm{U}=\mathrm{V}=\Psi=0, \frac{\partial \theta}{\partial y}=0$ (top side wall),

At $\mathrm{Y}=1 \mathrm{U}=\mathrm{V}=\Psi=0, \frac{\partial \theta}{\partial y}=0$ (bottom side wall),

The internal circular cylinder: $\mathrm{U}=\mathrm{V}=\Psi=0, \theta=1$.

The conditions have been applied to permeable surfaces between porous partition and nano-fluid are characterized as:

$$
\begin{aligned}
\theta_{\mathrm{po}}=\theta_{\mathrm{na}}, \frac{\partial \theta_{\mathrm{na}}}{\partial \mathrm{X}}= & \frac{\mathrm{K}_{\mathrm{eff}}}{\mathrm{K}_{\mathrm{na}}} \frac{\partial \theta_{\mathrm{po}}}{\partial \mathrm{X}}, \Psi_{\mathrm{po}}=\Psi_{\mathrm{na}}, \\
& \frac{\partial \Psi_{\mathrm{na}}}{\partial \mathrm{X}}=\frac{\partial \Psi_{\mathrm{po}}}{\partial \mathrm{X}}, \Omega_{\mathrm{po}}=\Omega_{\mathrm{na}}, \\
& \frac{\partial \Omega_{\mathrm{na}}}{\partial \mathrm{X}}=\frac{\partial \Omega_{\mathrm{po}}}{\partial \mathrm{X}}, \\
& \mu_{\mathrm{po}}\left(\frac{\partial \mathrm{U}_{\mathrm{po}}}{\partial \mathrm{Y}}+\frac{\partial \mathrm{V}_{\mathrm{po}}}{\partial \mathrm{X}}\right) \\
& =\mu_{\mathrm{na}}\left(\frac{\partial \mathrm{U}_{\mathrm{na}}}{\partial \mathrm{Y}}+\frac{\partial \mathrm{V}_{\mathrm{na}}}{\partial \mathrm{X}}\right), \\
& \mathrm{P}_{\mathrm{po}}=\mathrm{P}_{\mathrm{na}}, \frac{\partial \mathrm{P}_{\mathrm{po}}}{\partial \mathrm{X}}=\frac{\partial \mathrm{P}_{\mathrm{na}}}{\partial \mathrm{Y}}
\end{aligned}
$$

The local and the mean of Nusselt number for hot wall could be expressed in the form:

$$
\mathrm{Nu}_{\text {local }}=\frac{\mathrm{K}_{\mathrm{na}}}{\mathrm{K}_{\mathrm{fl}}} \frac{1}{\pi} \frac{\partial \theta}{\partial \mathrm{n}}, \mathrm{Nu}_{\mathrm{ave}}=\frac{\mathrm{K}_{\mathrm{na}}}{\mathrm{K}_{\mathrm{fl}}} \int_{0}^{1} \frac{\partial \theta}{\partial \mathrm{n}} \mathrm{dy}
$$

\begin{tabular}{|c|c|c|c|}
\hline $\mathbf{R a}$ & \multicolumn{2}{|c|}{ Mean Nusselt number at hot wall } & Error (\%) \\
\hline & Current research & Chamkha and Ismae [73] & \\
\hline $10^{4}$ & 1.3475 & 1.24 & -0.6948 \\
\hline $10^{6}$ & 6.332 & 6.45 & 1.829 \\
\hline
\end{tabular}

In the present work, Comsol Multiphysics software had been utilized to solve the dimensionless complex governing equation of heat transfer in each layer with the boundary conditions. The numerical procedure in COMSOL is done by selecting the model wizard, after that we choose the dimension of the problem space which is 2D. Laminar fluid flow with heat transfer was added to perform the interfaces of physics under the steady-state conditions. The computational domain of the wavy enclosure with the inner cylinder had been built and designed within the CFD software. After that the numerical grid had been generated and in order to check the best number of grids, mesh independent study had been done as illustrated in Figure 2. Also, in order to find out the accuracy of the present work numerical results a validation had been done with the previous published works in terms of streamlines, isotherms as in Figure 3 and in terms of Nusselt number as in Table 1.

Table 1. Comparisons of the mean of Nusselt number between the current and A. J. Chamkha and M. A. Ismael, the result for a various $\mathrm{Ra}, \varphi=0.05$, when $\mathrm{Da}=10^{-1}, \mathrm{~A}=2, \mathrm{Xp}=0.50$

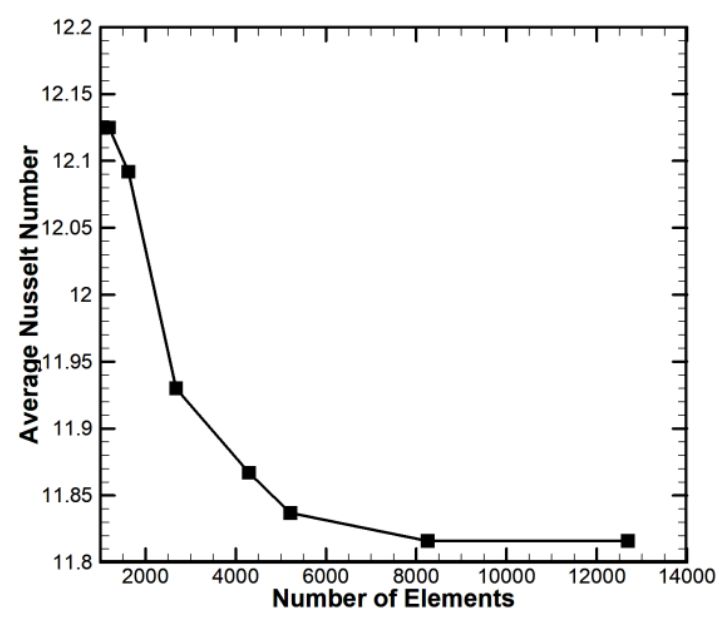

Figure 2. Mesh independent study 
Chamkha and Ismael [73]

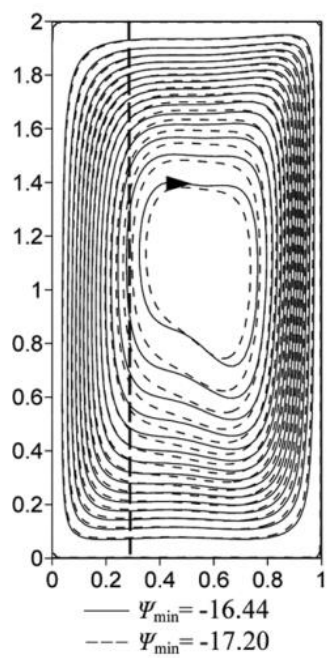

current study

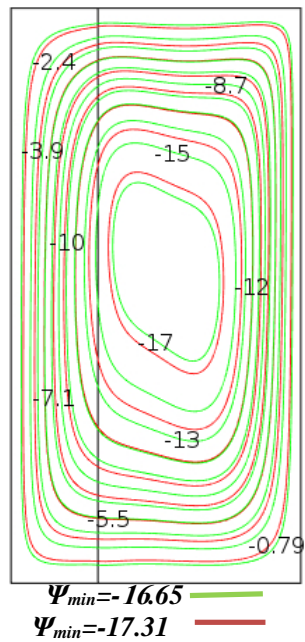

Figure 3. Streamlines for $\mathrm{Ra}=10^{5}, \mathrm{Xb}=0.50, \varphi=0, \mathrm{Da}=10^{-1}$, $\mathrm{A}=2$ (undashed lines), and $\varphi=0.05$ (dashed lines) for Chamkha and Ismael [73] and and $\varphi=0.05$ (green lines) $\varphi=0$ (red lines), for the current research

\section{RESULTS AND DISCUSSION}

In the current research, the free convection flow in a differentially heated cold wavy enclosure with internal heated cylinder in two layers of saturated porous media /nanofluid and nanofluid is examined numerically. The nanofluid is composed of Ag nanoparticles (its physical characteristics have been tabulated in Table 2) and the main fluid (water). The ranges of dimensionless parameters are as follows: $\mathrm{Ra}=10^{3}$ $10^{7}, \varphi=0-0.1, \mathrm{Da}=10^{-5}-10^{-1}$, the vertical location of the internal cylinder $\delta=-0.2-+0.2$, internal cylinder radius $\mathrm{R}=0.1$ -0.4 , wavy wall undulation number: $\mathrm{N}=0-3$.
Table 2. Thermo-physical characteristics of main fluid (pure water) and nanoparticles [54]

\begin{tabular}{ccc}
\hline characteristics & water & Ag \\
\hline $\mathrm{Cp}(\mathrm{J} / \mathrm{kg} \mathrm{k})$ & 4179 & 235 \\
$\rho(\mathrm{kg} / \mathrm{m} 3)$ & 997.1 & 10,500 \\
$\mathrm{~K}(\mathrm{~W} / \mathrm{m} . \mathrm{k})$ & 0.613 & 429 \\
$\beta(1 / \mathrm{k})$ & $21 \times 10^{-5}$ & $1.89 \times 10^{-5}$ \\
$\mu(\mathrm{kg} / \mathrm{m} . \mathrm{s})$ & 0.000372 & -----
\end{tabular}

\subsection{Influence of Rayleigh number}

Figure 4 (a-b) demonstrates the stream-line and isotherm lines, respectively for saturated porous media /nano-fluid (left layer) with same Ag nano-fluid (right layer) for a variety of magnitudes of Rayleigh's numbers at $\mathrm{X}_{\mathrm{p}}=0.5, \varphi=0.05$, $\mathrm{Da}=0.001, \mathrm{~N}=3, \mathrm{R}=0.2, \delta=0.2$. Based on the contours images, it could be noted from Figure 4 (a) that when Rayleigh's number increases, the maximum absolute magnitude of stream function will increase as a result of increasing the fluid flow circulation intensity. Actually, the physical reason behind this is that increasing Rayleigh's number increases the buoyancy and free convection effect which increases the stream function. For instance, in the case of the increase of the Rayleigh's number from $\mathrm{Ra}=10^{3}$ into $\mathrm{Ra}=10^{7}$, the maximum stream function will increase from $\Psi_{\max }=-0.072483$ into $\Psi_{\max }=-38$. 215 , respectively. Concerning the isotherms, it may be noted from Figure 4 (b) that in case of $\mathrm{Ra}=10^{4}$ (i.e., low Rayleigh number), the isotherms lines generally have uniform shapes because of the weak effect of convection as in this case the conduction heat transfer mode is the dominating. However, as the Rayleigh number increases into $\mathrm{Ra}=10^{7}$ the isotherms lines change the shapes into curved non-uniform shape. Physically increasing Rayleigh number increases the free convection effect and for that we see irregularity in the shape of isotherms layer as Rayleigh number increase which leads to make the natural convection becomes dominant.

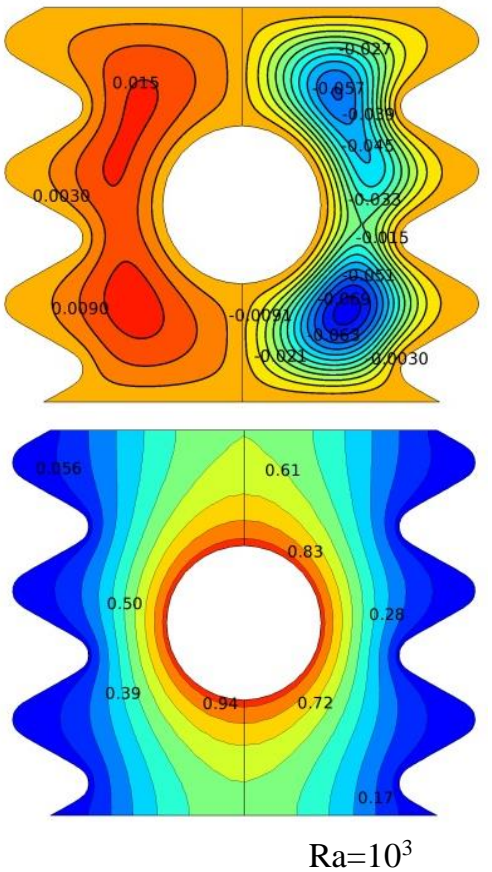

$\mathrm{Ra}=10^{3}$
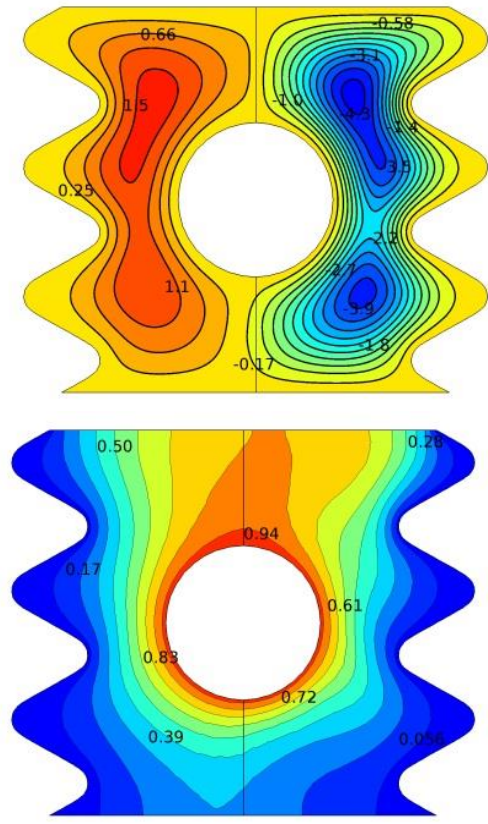

$\mathrm{Ra}=10^{5}$
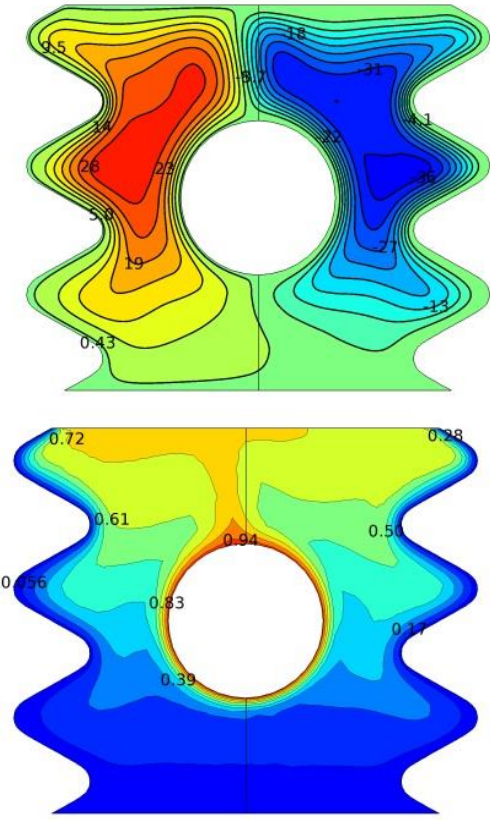

$\operatorname{Ra}=10^{7}$

Figure 4. Stream-lines (top) and isotherms (bottom) for a variety of Rayleigh number magnitudes at $[\mathrm{Da}=0.001, \delta=0, \varphi=0.05$, $\mathrm{R}=0.1]$ 


\subsection{Influence of Darcy number}

Figure $5(a-b)$ demonstrates the stream-line and isotherm lines, respectively for the saturated porous media /nano-fluid (left layer) with same $\mathrm{Ag}$ nano-fluid (i.e. the right layer) for a variety of magnitudes of Darcy numbers at $\mathrm{X}_{\mathrm{p}}=0.5, \varphi=0.05$, $\mathrm{Ra}=10^{6}, \mathrm{~N}=3, \mathrm{R}=0.2, \delta=0.2$. It could be seen that with the increase in Darcy's number, the strength of cell in the left layer (saturated porous media/nanofluid) will be increased. The physical reason behind that is due to increasing the permeability in the porous media which helps the nanofluid penetrate through the porous media. So that the fluid flow strength will increase. For example, when the Darcy number increases from $\mathrm{Da}=10^{-5}$ into $\mathrm{Da}=10^{-3}$, the maximum stream function in the left layer will increase from $\Psi_{\min }=-0.22104$ into $\Psi_{\min }=10.283$. On the other hand, increasing Darcy's number will lead to changing their shapes from vertical shapes at low Darcy number $\left(\mathrm{Da}=10^{-5}\right)$ which conduction heat transfer is dominant into horizontal shapes at high Darcy number magnitude ( $\left.\mathrm{Da}=10^{-1}\right)$ indicating that the convection mode will be dominating. The physical reason is that increasing Darcy number changes the heat transfer mode from conduction into convection mode.
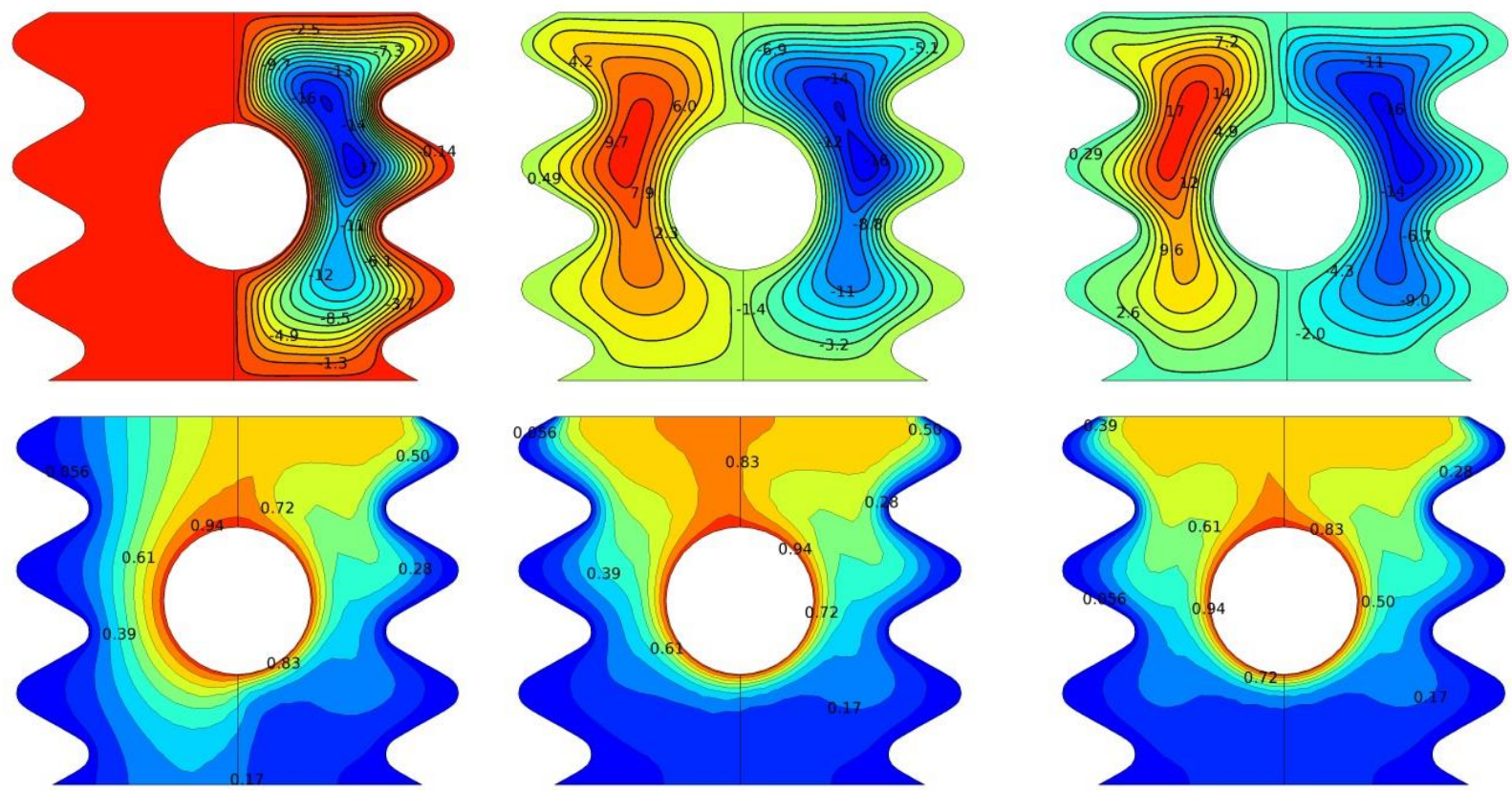

$\mathrm{Da}=10^{-5}$

$\mathrm{Da}=10^{-3}$

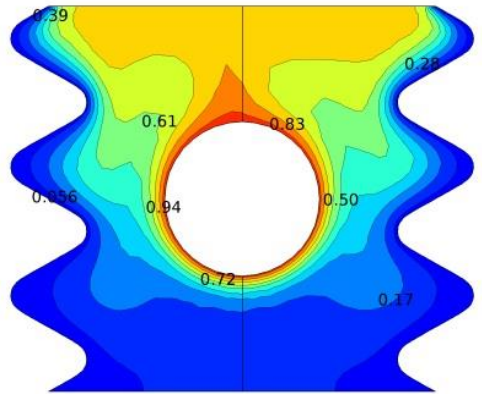

$\mathrm{Da}=10^{-1}$

Figure 5. Streamlines (top) and isotherms (bottom) for various Darcy number magnitudes at $\left[\mathrm{Ra}=10^{6}, \delta=0, \varphi=0.05, \mathrm{R}=0.1\right]$
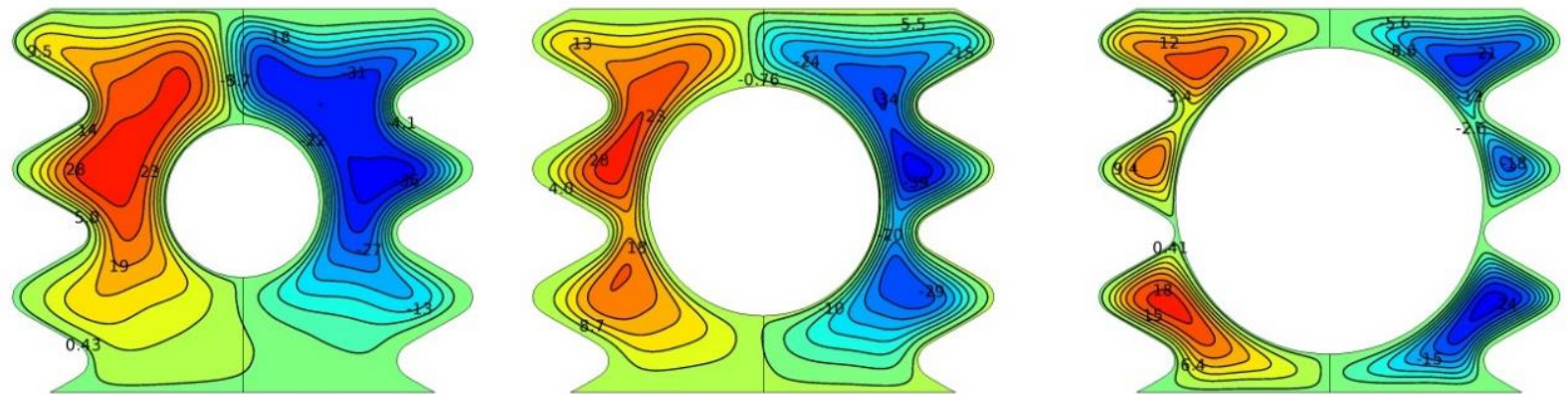

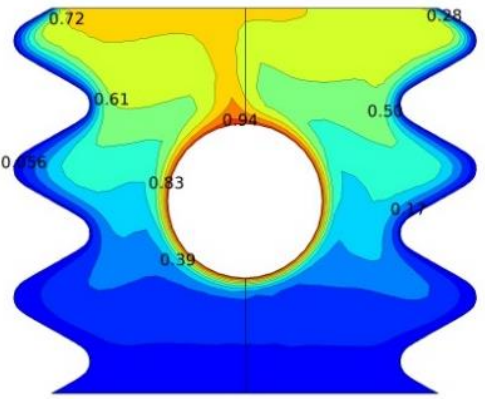

$\mathrm{R}=0.2$

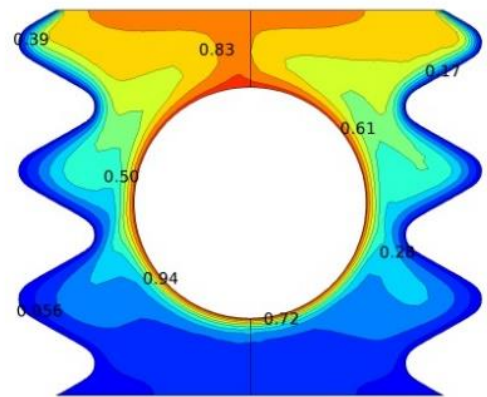

$\mathrm{R}=0.3$

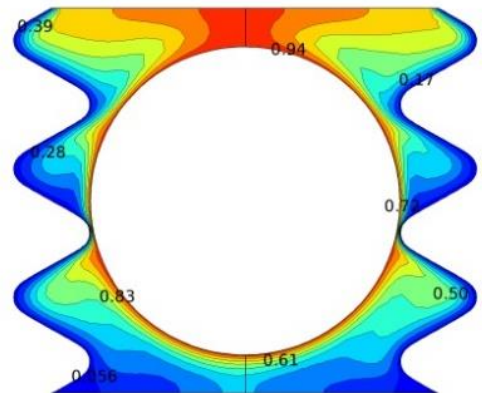

$\mathrm{R}=0.4$

Figure 6. Streamlines (top) and isotherms (bottom) for various inner circular radius at $\left[\mathrm{Ra}=10^{6}, \mathrm{Da}=0.001, \delta=0, \varphi=0.05\right]$ 

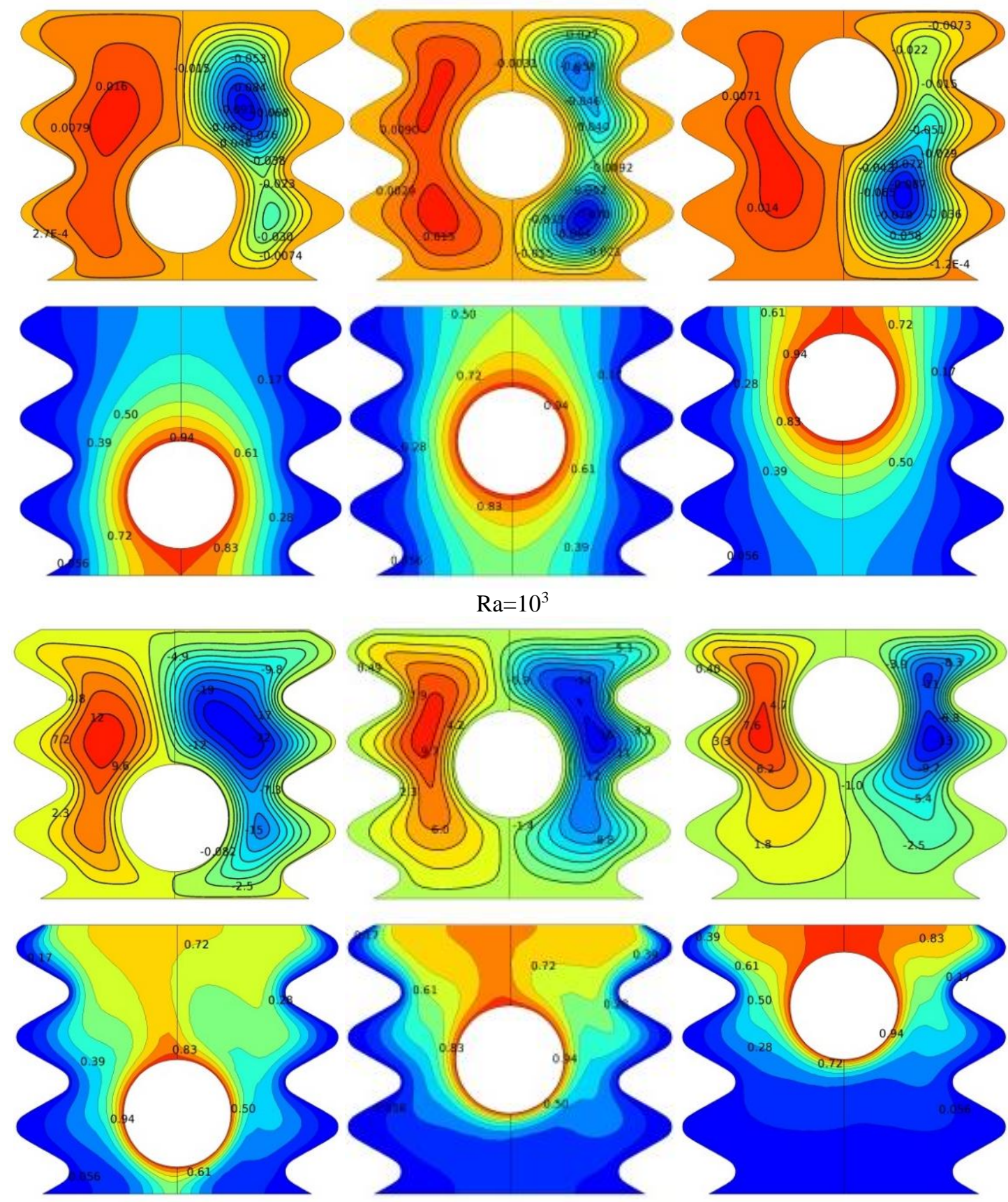

$\mathrm{Ra}=10^{6}$

Figure 7. Streamlines (top) and isotherms (bottom) for various inner circular cylinder position magnitudes at $\left[\mathrm{Da}=10^{-3}, \delta=0\right.$, $\varphi=0.05, \mathrm{R}=0.1]$

\subsection{Influence of cylinder radius}

Figure $6(a-b)$ demonstrates the streamline and isotherm lines, respectively for saturated porous media /nano-fluid (left layer) with the same $\mathrm{Ag}$ nano-fluid (right layer) for a variety of magnitudes of internal cylinder radius at $\mathrm{X}_{\mathrm{p}}=0.5, \varphi=0.05$, $\mathrm{Ra}=10^{6}, \mathrm{Da}=10^{-3}, \mathrm{~N}=3, \delta=0.2$. It could be observed that the fluid flow strength reduces as the internal heated cylinder increases. For example, when the internal radius increases from $\mathrm{R}=0.20$ to $\mathrm{R}=0.40$, the maximum stream function increases from $\Psi_{\max }=17.107$ into $\Psi_{\max }=7.5905$. This is due to the fact that when internal heated radius increases, the flow exchange area between the cylinder and the wavy enclosure reduces and the collision of fluid particle will reduce, which reduces the kinetic energy leading to the decrease in the fluid flow stream function. Also, there is another reason for the reduction in the fluid flow strength which is that with increasing the cylinder diameter, the buoyancy force will decline and the problem becomes closer to conduction heat transfer. Therefore, it can be concluded that the internal cylinder with radius $\mathrm{R}=0.2$ is the best case for determining the internal cylinder radius.

\subsection{Influence of cylinder position}

Figure $7(a-b)$ demonstrates the streamline and isotherm lines, respectively for saturated porous media /nano-fluid (left layer) with the same Ag nano-fluid (right layer) for a variety of magnitudes of internal cylinder positions and Rayleigh umbers at $\mathrm{X}_{\mathrm{p}}=0.5, \varphi=0.05, \mathrm{Da}=10^{-3}, \mathrm{~N}=3, \mathrm{R}=0.2$. It could be observed that when the cylinder moves in a vertical way in the upper direction, the fluid flow strength will be at its maximum 
magnitudes below the cylinder and forming two internal cells. While as the cylinder moves in a vertical manner downwards, the two internal circles will be above the cylinder. Now, at low Rayleigh's number $\left(\mathrm{Ra}=10^{3}\right)$ when the internal heated cylinder moves from the wavy enclosure's center vertically downward or upward, in other words, from $\delta=0$ into $\delta=-0.20$ or $\delta=+0.20$, the maximal stream function reduces. While at high Rayleigh number magnitudes, the behavior is quite different. For example, when the internal cylinder moves vertically downwards, in other words, from $\delta=0$ into $\delta=-0.20$, the maximum stream function increases from $\Psi_{\max }=-17.069$ into $\Psi_{\max }=-23.097$. While a quite reverse behavior in the case where the cylinder moves in a vertical way upwards i.e., from $\delta=0$ into $\delta=+0.20$, the maximal stream function decreases from $\Psi_{\max }=-17.069$ into $\Psi_{\max }=-13.356$. with respect to the isotherm lines that the internal circular position effect on isotherms distribution and heat transfer will cover most of the space between the wavy enclosure and the internal circle in the case where the internal cylinder moves vertically downwards from $\delta=0$ onto $\delta=-0.20$.

\subsection{Number of undulations}

Figure $8(a-b)$ demonstrates the streamline and isotherm lines, respectively for saturated porous media /nano-fluid (left layer) with similar Ag nano-fluid (layer on the right) for a variety of magnitudes of number of undulation at $\mathrm{X}_{\mathrm{p}}=5 \times 10^{-1}$, $\varphi=5 \times 10^{-2}, \mathrm{Ra}=10^{6}, \mathrm{Da}=10^{-3}, \delta=0, \mathrm{R}=0.2$. It could be observed that when $\mathrm{N}=0$, an internal circle of stream function is formed above the cylinder. When the undulations' number rises to $\mathrm{N}=1$, the internal cell of streamlines takes a shape like the wavy enclosure. The stream function reduces from $\Psi_{\max }=22.727$ into $\Psi_{\max }=15.599$ when the undulations number rises from $\mathrm{N}=0$ (square enclosure) into $\mathrm{N}=1$, after that the maximum stream function increases into $\Psi_{\max }=17.919$ at $\mathrm{N}=2$. However, there are no effects on stream function when the number of undulations increases to $\mathrm{N}=3$.

\subsection{Nusselt number}

To examine the amount of heat transfer, the Nusselt number is the most significant parameters which has been deduced.
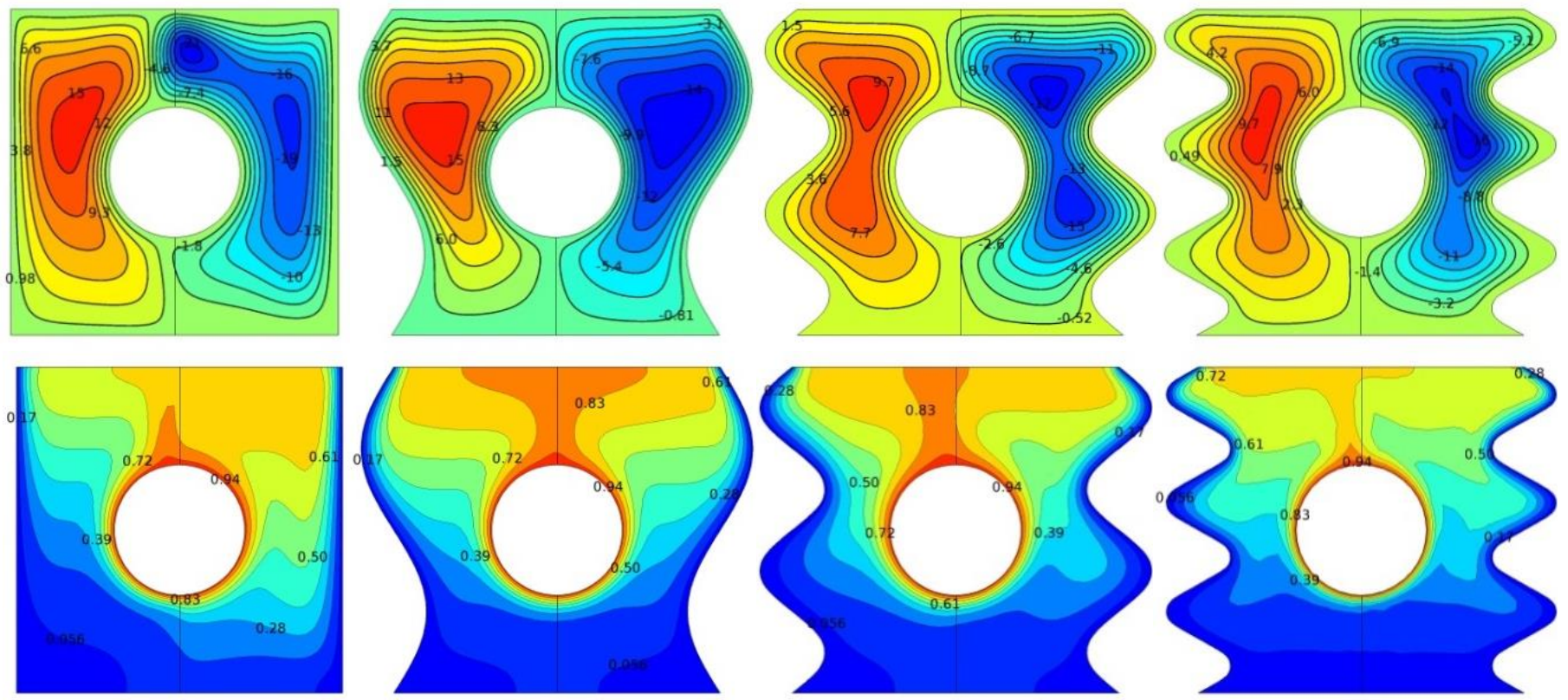

Figure 8. Streamlines (top) and isotherms (bottom) for various number of undulations magnitudes at $\left[\mathrm{Ra}=10^{6}, \mathrm{Da}=0.001, \delta=0\right.$, $\varphi=0.05, \mathrm{R}=0.1]$ and Rayleigh's number on local Nusselt number profile. It could be observed that increasing Rayleigh's number from $\mathrm{Ra}=10^{4}$ into $\mathrm{Ra}=10^{6}$ will lead to an obvious increasing in the local Nusselt number profile. Besides that, for constant magnitude of Rayleigh number, increasing the nano-fluid volume fraction from $\varphi=0$ to $\varphi=0.1$, the local Nusselt number profile will increase also which leads to the enhancement of heat transfer characteristics. With respect to impact of Darcy's number on local Nusselt number profile as presented in Figure 10. Increasing Darcy number yields in enhancing the amount of heat transfer. The reason behind that is that when Darcy's number increases, the buoyancy force and natural convection increase and mode of heat transfer changes from conduction mode at low Darcy number into convection mode in the high Darcy number. Figure 11 depicts the impact of number of undulations on local Nusselt number profile at $\mathrm{Ra}=10^{6}, \mathrm{Da}=10^{-}$ 3 . It is noted that the flat vertical wall $(\mathrm{N}=0)$ gives the highest local Nusselt's number profile. It has been noted that increasing the number of undulations from $\mathrm{N}=0$ into $\mathrm{N}=1$, will reduce the local Nusselt number profile. This behavior also happens when the number of undulations increases to $\mathrm{N}=2$. However, there is no impact for increasing the number of undulations after $\mathrm{N}=2$ on the local Nusselt number profile.

The impact of Rayleigh and Darcy's numbers and nanofluid volume fraction on mean of Nusselt number is obtainable in Figure 12. This indicates that increasing Rayleigh and Darcy number as well as the concentration of nano-fluid will augment the average Nusselt number, which leads to remarkable enhancements in the amount of heat transfer. For example when Rayleigh's number increases from $\left[10^{4}\right]$ to $\left[10^{6}\right]$, the average Nusselt number improved from $\mathrm{Nu}=5.97$ to $\mathrm{Nu}=11.4$, respectively at constant nanofluid volume fraction equal to $\varphi=0.1$ as illustrated in Figure 12 (a). With respect to the impact of Darcy number when the nanofluid volume fraction stayed constant, it is seen that Darcy number increases from $\mathrm{Nu}=8.56$ at $\left[\mathrm{Da}=10^{-5}\right]$ into $\mathrm{Nu}=12.43$ at $\left[\mathrm{Da}=10^{-1}\right]$ as illustrated in Figure 12(b). in addition to that, when the Rayleigh number stays constant at $\mathrm{Ra}=10^{4}$ and the nanofluid volume fraction increases from $\varphi=0.05$, into $\varphi=0.05$, The $\mathrm{Nu}$ will increase from $\mathrm{Nu}=5.1$ into $\mathrm{Nu}=5.97$.
Figure 9 demonstrates the impact of nanofluid volume fraction 


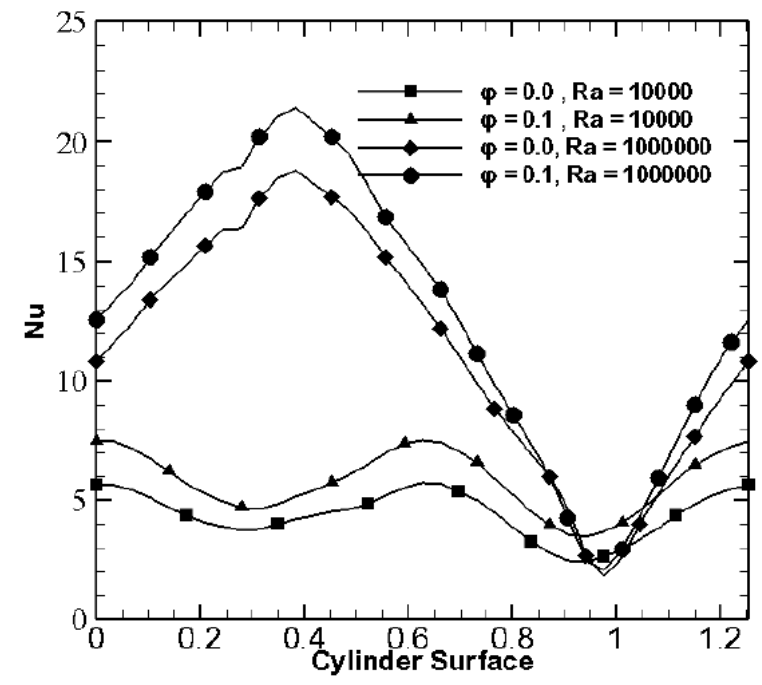

Figure 9. Local number of Nusselt profile for different Rayleigh number magnitudes and nanofluid volume fraction at $\left[\mathrm{Ra}=10^{6}, \mathrm{Da}=0.001, \delta=0, \varphi=0.05, \mathrm{R}=0.1\right]$

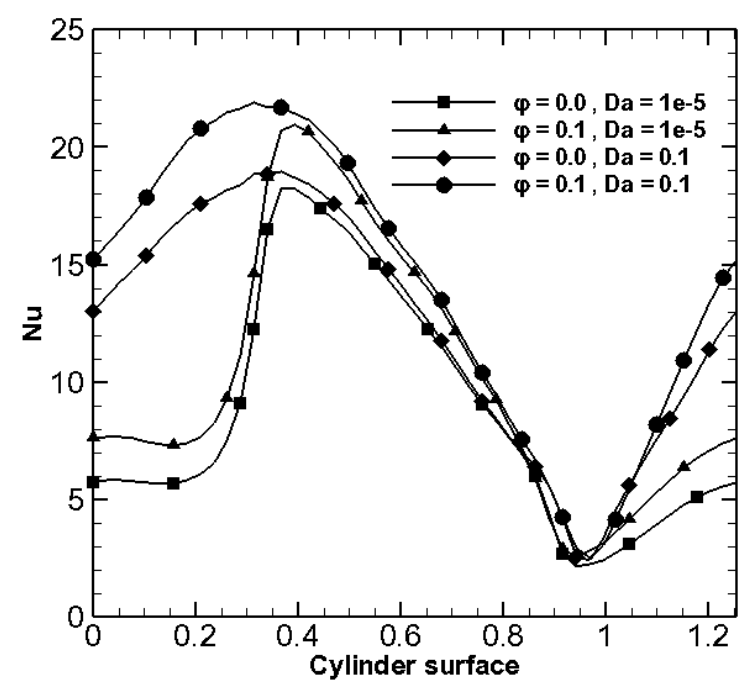

Figure 10. Local number of Nusselt profile for different Darcy's number magnitudes and nanofluid volume fraction at $\left[\mathrm{Ra}=10^{6}, \mathrm{Da}=0.001, \delta=0, \varphi=0.05, \mathrm{R}=0.1\right]$

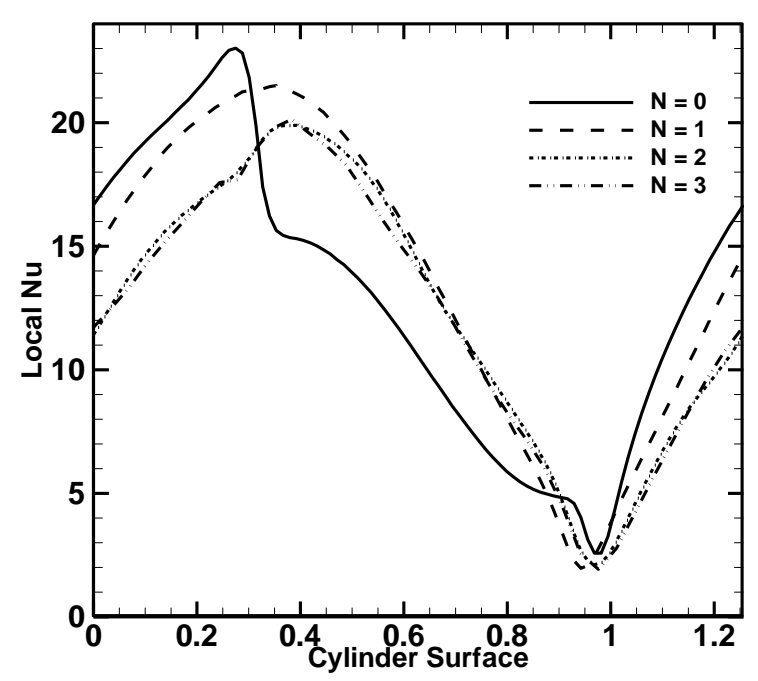

Figure 11. Local number of Nusselt profile along the internal cylinder for various magnitudes of number of undulations at $\left[\mathrm{Ra}=10^{6}, \mathrm{Da}=0.001, \delta=0, \varphi=0.05, \mathrm{R}=0.1\right]$
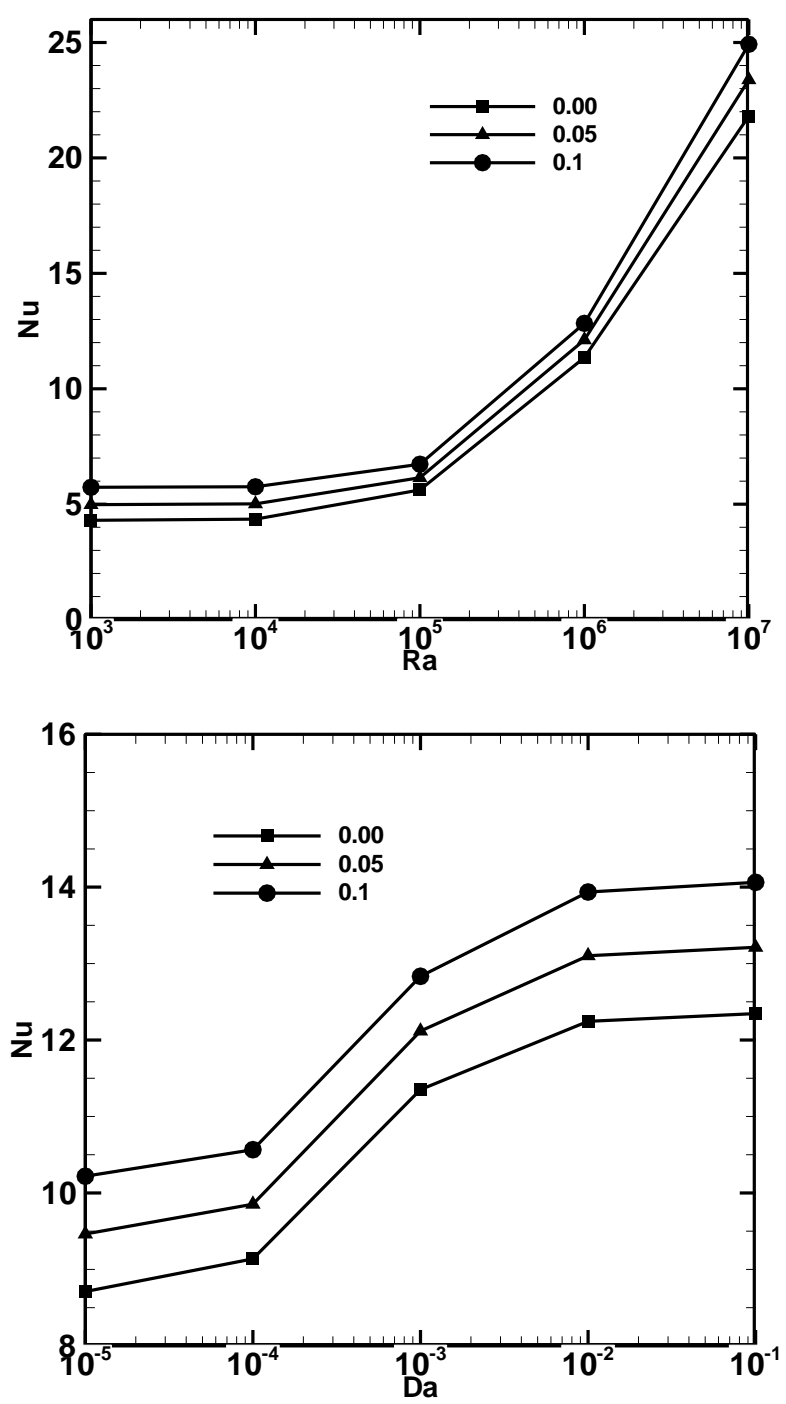

Figure 12. The number of Nusselt's mean along the internal cylinder versus (a) various Rayleigh's number magnitudes (b) various magnitudes of Darcy number under various concentration of nanofluid volume fraction at $[\mathrm{Da}=0.001$, $\delta=0, \varphi=0.05, \mathrm{R}=0.1]$

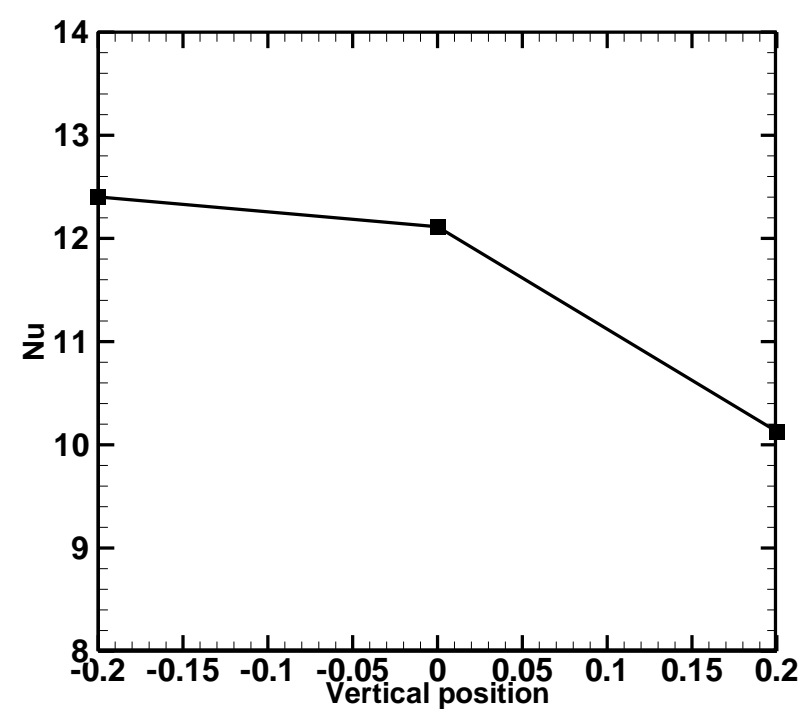

Figure 13. Mean of Nusselt number along the internal cylinder versus various magnitude of vertical location at $\left[\mathrm{Da}=0.001, \delta=0, \varphi=0.05, \mathrm{Ra}=10^{6}\right]$ 

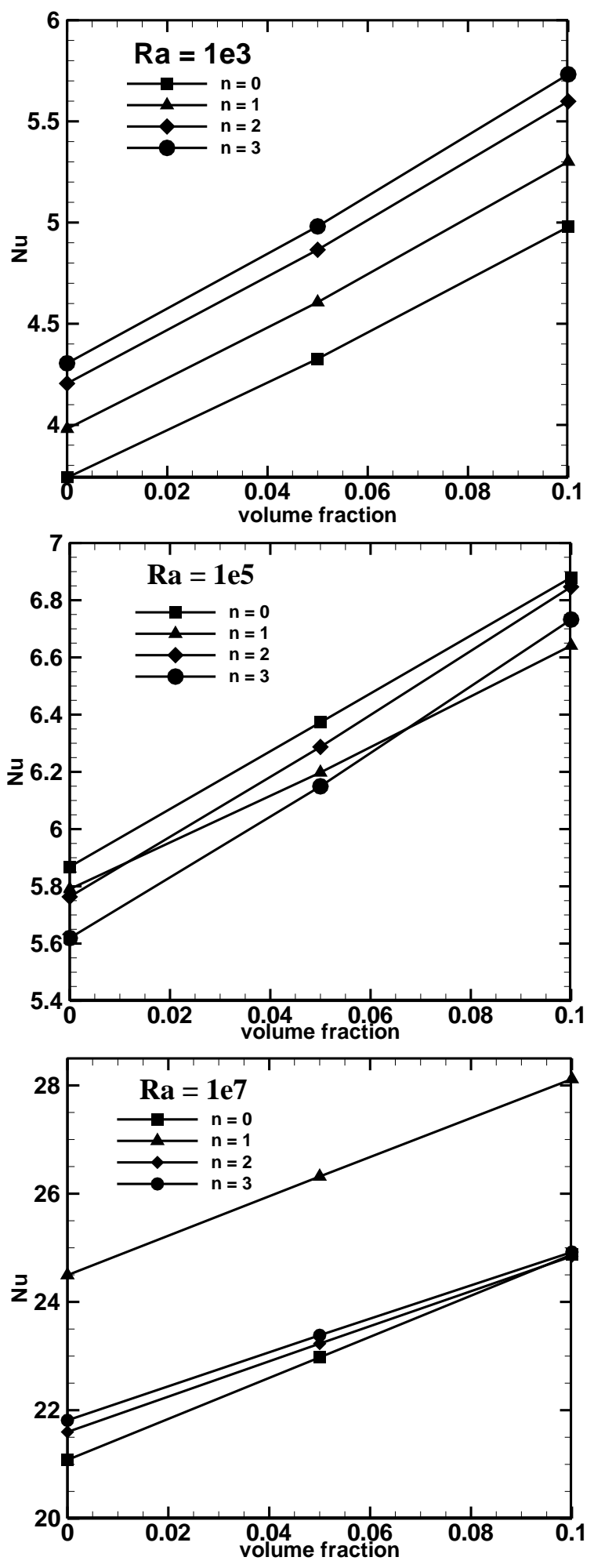

Figure 14. Mean of Nusselt number along the internal circular cylinder versus nanofluid volume fraction under various magnitude of number of undulations and Rayleigh numbers at $[\mathrm{Da}=0.001, \delta=0, \varphi=0.05]$

Figure 13 explains the impact of the vertical location of internal cylinder in the mean of Nusselt number. When internal cylinder moves from the center of wavy enclosure $(\delta=0)$ vertically downward $(\delta=-0.2)$, the mean of the Nusselt number profile will increase, which enhances the heat transfer. While in case where the cylinder moves in upper direction (from $\delta=0$ to $\delta=+0.20$ ), the Nusselt's number mean will reduce, which reduces the amount of heat transfer. Finally, the impact of the number of undulations on the Nusselt number's mean is discussed in Figure 14 for a different number of Rayleigh. At low number of Rayleigh magnitude $\left(\mathrm{Ra}=10^{3}\right)$ as in Figure 14 (a), it has been noted that the increase in the number of undulation increases the mean of Nusselt number that leads to augmenting the amount of heat transfer. Where the best amount of heat transfer is for $\mathrm{N}=3$ and minimum is at $\mathrm{N}=0$. This behavior is quite reverse when Rayleigh's number increases into $10^{5}$ as in Figure 14 (b) where the best amount of heat transfer is for $\mathrm{N}=0$ and lowest is at $\mathrm{N}=3$. At very high magnitude of Rayleigh's number $\left(10^{7}\right)$ as in Figure 14 (c), when the number of undulations is $\mathrm{N}=1$ gives the best amount of heat transfer in comparison with a flat vertical wall and others undulations number. In this way, it is recommended that for better amount of heat transfer to move the internal cylinder with radius $(R=0.2)$ vertically downward $(\delta=-0.20)$ with number of undulations $(\mathrm{N}=1)$.

\section{CONCLUSIONS}

Natural convection heat transfer in wavy enclosure which has an internal circular cylinder filling with $\mathrm{Ag}$ nano-fluid and saturated porous media was numerically researched. The Darcy-Brinkman method has been utilized to couple the momentum equation between the nanofluid and the porous domains. The effect of different crucial parameters like the Rayleigh number, Darcy number, nanofluids volume fraction, internal cylinder's radius, cylinder vertical position, and number of undulation on field flow and heat transfer has been studied. The major findings can be summarized in the following points:

The increasing of the value of Rayleigh and Darcy significantly affects the fluid flow and heat transfer rate.

It was discovered that the average Nusselt number of right layer (Ag nanofluids) is increasing/ decreasing function of Rayleigh's number then regarding the left layer (saturated porous media/nanofluid) the average Nusselt number gradually increasing /decreasing with augmentation of Darcy number.

Moreover, the value of average Nusselt's number strongly depends on undulations number and the volume fraction of $\mathrm{Ag}$ nanofluids.

It is found that the increase in the internal circular radius leads to reducing the space between the internal body and the wavy enclosure which reduces both the fluid flow strength and the average Nusselt's number.

Eventually, it has been observed that the optimum geometrical parameters for enhancing heat transfer of the wavy enclosure for the internal circular cylinder with a radius of $(\mathrm{R}=0.2)$ and vertically downward $(\delta=-0.20)$ with undulations' number $(\mathrm{N}=1)$

\section{ACKNOWLEDGMENT}

We would like to express our thanks to the respected editors of International Journal of Heat and Technology and the respected reviewers for their comments that clearly enhance the manuscript. Also, we would like to thank our institution "Al-Mustaqbal University College" for the financial support (www.mustaqbal-college.ed.iq). 


\section{REFERENCES}

[1] Khanafer, K.M., Chamkha, A.J. (1998). Hydromagnetic natural convection from an inclined porous square enclosure with heat generation. Numerical Heat Transfer, Part A Applications, 33(8): 891-910. https://doi.org/10.1080/10407789808913972

[2] Baytas, A.C., Pop, I. (1999). Free convection in oblique enclosures filled with a porous medium. International Journal of Heat and Mass Transfer, 42(6): 1047-1057. https://doi.org/10.1016/S0017-9310(98)00208-7

[3] Baytaş, A. (2000). Entropy generation for natural convection in an inclined porous cavity. International Journal of Heat and Mass Transfer, 43(12): 2089-2099. https://doi.org/10.1016/S0017-9310(99)00291-4

[4] Baytaş, A., Pop, I. (2001). Natural convection in a trapezoidal enclosure filled with a porous medium. International Journal of Engineering Science, 39(2): 125134. https://doi.org/10.1016/S0017-9310(99)00291-4

[5] Al-Amiri, A.M. (2002). Natural convection in porous enclosures: the application of the two-energy equation model. Numerical Heat Transfer: Part A: Applications, 41(8):

$817-834$ https://doi.org/10.1080/10407780290059369

[6] Kumar, R., Shalini, B. (2003). Natural convection in a thermally stratified wavy vertical porous enclosure. Numerical Heat Transfer: Part A: Applications, 43(7): 753-776.

[7] Bourich, M., Hasnaoui, M., Amahmid, A. (2004). Double-diffusive natural convection in a porous enclosure partially heated from below and differentially salted. International Journal of Heat and fluid flow, 25(6): 1034-1046.

https://doi.org/10.1016/j.ijheatfluidflow.2004.01.003

[8] Varol, Y., Oztop, H.F., Varol, A. (2006). Free convection in porous media filled right-angle triangular enclosures. International Communications in Heat and Mass Transfer, 33(10): 1190-1197. https://doi.org/10.1016/j.icheatmasstransfer.2006.08.00 8

[9] Varol, Y., Oztop, H.F., Varol, A. (2007). Effects of thin fin on natural convection in porous triangular enclosures. International Journal of Thermal Sciences, 46(10): 10331045. https://doi.org/10.1016/j.ijthermalsci.2006.11.001

[10] Saeid, N.H. (2007). Conjugate natural convection in a porous enclosure: Effect of conduction in one of the vertical walls. International Journal of Thermal Sciences, 46(6):

531-539. https://doi.org/10.1016/j.ijthermalsci.2006.08.003

[11] Zahmatkesh, I. (2008). On the importance of thermal boundary conditions in heat transfer and entropy generation for natural convection inside a porous enclosure. International Journal of Thermal Sciences, 47(3): $\quad 339-346$ https://doi.org/10.1016/j.ijthermalsci.2007.02.008

[12] Varol, Y., Oztop, H.F., Pop, I. (2008). Numerical analysis of natural convection for a porous rectangular enclosure with sinusoidally varying temperature profile on the bottom wall. International Communications in Heat and Mass Transfer, 35(1): 56-64 https://doi.org/10.1016/j.icheatmasstransfer.2007.05.01 5

[13] Khanafer, K., Al-Azmi, B., Marafie, A., Pop, I. (2009). Non-Darcian effects on natural convection heat transfer in a wavy porous enclosure. International Journal of Heat and Mass Transfer, 52(7-8): 1887-1896. https://doi.org/10.1016/j.ijheatmasstransfer.2008.08.040

[14] Aleshkova, I.A., Sheremet, M.A. (2010). Unsteady conjugate natural convection in a square enclosure filled with a porous medium. International Journal of Heat and Mass Transfer, 53(23-24): 5308-5320. https://doi.org/10.1016/j.ijheatmasstransfer.2010.07.025

[15] Basak, T., Roy, S., Matta, A., Pop, I. (2010). Analysis of heatlines for natural convection within porous trapezoidal enclosures: Effect of uniform and nonuniform heating of bottom wall. International Journal of Heat and Mass Transfer, 53(25-26): 5947-5961. https://doi.org/10.1016/j.ijheatmasstransfer.2010.07.026

[16] Sankar, M., Park, Y., Lopez, J.M., Do, Y. (2011). Numerical study of natural convection in a vertical porous annulus with discrete heating. International Journal of Heat and Mass Transfer, 54(7-8): 1493-1505. https://doi.org/10.1016/j.ijheatmasstransfer.2010.11.043

[17] Khandelwal, M.K., Bera, P., Chakrabarti, A. (2012). Influence of periodicity of sinusoidal bottom boundary condition on natural convection in porous enclosure. International Journal of Heat and Mass Transfer, 55(1112): 2889-2900 https://doi.org/10.1016/j.ijheatmasstransfer.2012.02.028

[18] Lam, P.A.K., Prakash, K.A. (2014). A numerical study on natural convection and entropy generation in a porous enclosure with heat sources. International Journal of Heat and Mass Transfer, 69: 390-407. https://doi.org/10.1016/j.ijheatmasstransfer.2013.10.009

[19] Bhardwaj, S., Dalal, A., Pati, S. (2015). Influence of wavy wall and non-uniform heating on natural convection heat transfer and entropy generation inside porous complex enclosure. Energy, 79: 467-481. https://doi.org/10.1016/j.energy.2014.11.036

[20] Ahmed, S.E., Hussein, A.K., El-Aziz, M.A., Sivasankaran, S. (2016). Conjugate natural convection in an inclined square porous enclosure with finite wall thickness and partially heated from its left sidewall. Heat Transfer Research, 47(4). https://doi.org/10.1615/HeatTransRes.2016007964

[21] Erbay, L., Altaç, Z., Sülüs, B. (2003). An analysis of the entropy generation in a square enclosure. Entropy, 5(5): 496-505. https://doi.org/10.3390/e5050496

[22] Akbari, M., Behzadmehr, A., Shahraki, F. (2008). Fully developed mixed convection in horizontal and inclined tubes with uniform heat flux using nanofluid. International Journal of Heat and Fluid Flow, 29(2): 545556. https://doi.org/10.1016/j.ijheatfluidflow.2007.11.006

[23] Kahwaji, G., Ali, O.M. (2015). Numerical investigation of natural convection heat transfer from square cylinder in an enclosed enclosure filled with nanofluids. International Journal of Recent Advances in Mechanical

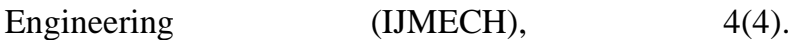
https://doi.org/10.14810/ijmech.2015.4401

[24] Selimefendigil, F., Öztop, H., Abu-Hamdeh, N. (2016). Natural convection and entropy generation in nanofluid filled entrapped trapezoidal cavities under the influence of magnetic field. Entropy, 18(2): 43. https://doi.org/10.3390/e18020043

[25] Angeli, D., Levoni, P., Barozzi, G.S. (2008). Numerical predictions for stable buoyant regimes within a square cavity containing a heated horizontal cylinder. 
International Journal of Heat and Mass Transfer, 51(3-4): 553-565.

https://doi.org/10.1016/j.ijheatmasstransfer.2007.05.007

[26] Xu, X., Sun, G., Yu, Z., Hu, Y., Fan, L., Cen, K. (2009) Numerical investigation of laminar natural convective heat transfer from a horizontal triangular cylinder to its concentric cylindrical enclosure. International Journal of Heat and Mass Transfer, 52(13-14): 3176-3186. https://doi.org/10.1016/j.ijheatmasstransfer.2009.01.026

[27] Kim, B.S., Lee, D.S., Ha, M.Y., Yoon, H.S. (2008). A numerical study of natural convection in a square enclosure with a circular cylinder at different vertical locations. International Journal of Heat and Mass Transfer, 51(7-8): 1888-1906. https://doi.org/10.1016/j.ijheatmasstransfer.2007.06.033

[28] Hussain, S.H., Hussein, A.K. (2010). Numerical investigation of natural convection phenomena in a uniformly heated circular cylinder immersed in square enclosure filled with air at different vertical locations. International Communications in Heat and Mass Transfer, 37(8):

$1115-1126$. https://doi.org/10.1016/j.icheatmasstransfer.2010.05.01 6

[29] Yoon, H.S., Ha, M.Y., Kim, B.S., Yu, D.H. (2009). Effect of the position of a circular cylinder in a square enclosure on natural convection at Rayleigh Number of 107. Physics of Fluids, 21(4): 047101. https://doi.org/10.1063/1.3112735

[30] Hussain, S.H., Hussein, A.K. (2011). Mixed convection heat transfer in a differentially heated square enclosure with a conductive rotating circular cylinder at different vertical locations. International Communications in Heat and Mass Transfer, 38(2): 263-274. https://doi.org/10.1016/j.icheatmasstransfer.2010.12.00 6

[31] Park, Y.G., Ha, M.Y., Choi, C., Park, J. (2014). Natural convection in a square enclosure with two inner circular cylinders positioned at different vertical locations. International Journal of Heat and Mass Transfer, 77: 501518.

https://doi.org/10.1016/j.ijheatmasstransfer.2014.05.041

[32] Park, Y., M. Ha., Yoon, H. (2013). Study on natural convection in a cold square enclosure with a pair of hot horizontal cylinders positioned at different vertical locations. International Journal of Heat and Mass Transfer, 65: 696-712. https://doi.org/10.1016/j.ijheatmasstransfer.2013.06.059

[33] Park, Y.G., Yoon, H.S., Ha, M.Y. (2012). Natural convection in square enclosure with hot and cold cylinders at different vertical locations. International Journal of Heat and Mass Transfer, 55(25-26): 79117925.

https://doi.org/10.1016/j.ijheatmasstransfer.2012.08.012

[34] Majdi, H.S., Abdulkadhim, A., Abed, A.M. (2019). Numerical investigation of natural convection heat transfer in a parallelogramic enclosure having an inner circular cylinder using liquid nanofluid. Frontiers in Heat and Mass Transfer, 2019. https://doi.org/10.5098/hmt.12.2

[35] Bararnia, H., Soleimani, S., Ganji, D. (2011). Lattice Boltzmann simulation of natural convection around a horizontal elliptic cylinder inside a square enclosure. International Communications in Heat and Mass Transfer, $\quad 38(10)$ : $1436-1442$. https://doi.org/10.1016/j.icheatmasstransfer.2011.07.01 2

[36] Mun, G.S., Seo, Y.M., Park, Y.G., Ha, M.Y. (2018). Natural convection in a cold enclosure with four hot inner cylinders in a diamond array (Part-II: effect of unequal horizontal and vertical distances of inner cylinders). International Journal of Heat and Mass Transfer, 120: 1365-1373.

https://doi.org/10.1016/j.ijheatmasstransfer.2017.05.086

[37] Lee, J., Ha, M., Yoon, H. (2010). Natural convection in a square enclosure with a circular cylinder at different horizontal and diagonal locations. International Journal of Heat and Mass Transfer, 53(25-26): 5905-5919. https://doi.org/10.1016/j.ijheatmasstransfer.2010.07.043

[38] Abdelmalek, Z., Tayebi, T., Dogonchi, A.S., Chamkha, A.J., Ganji, D.D., Tlili, I. (2020). Role of various configurations of a wavy circular heater on convective heat transfer within an enclosure filled with nanofluid. International Communications in Heat and Mass Transfer, 113: 104525. https://doi.org/10.1016/j.icheatmasstransfer.2020.10452 5

[39] Rostami, J. (2008). Unsteady natural convection in an enclosure with vertical wavy walls. Heat and Mass Transfer, 44(9): 1079-1087. https://doi.org/10.1007/s00231-007-0349-1

[40] Majdi, H.S., Abdulkadhim, A., Abed, A.M. (2019). Numerical investigation of natural convection heat transfer in a parallelogramic enclosure having an inner circular cylinder using liquid nanofluid. Frontiers in Heat and Mass Transfer. https://doi.org/10.5098/hmt.12.2

[41] Cho, C.C., Chen, C.L. (2012). Natural convection heat transfer performance in complex-wavy-wall enclosed cavity filled with nanofluid. International Journal of Thermal Sciences, 60: 255-263. https://doi.org/10.1016/j.ijthermalsci.2012.05.001

[42] Esmaeilpour, M., Abdollahzadeh, M. (2012). Free convection and entropy generation of nanofluid inside an enclosure with different patterns of vertical wavy walls. International Journal of Thermal Sciences, 52: 127-136. https://doi.org/10.1016/j.ijthermalsci.2011.08.019

[43] Cho, C.C., Chiu, C.H., Lai, C.Y. (2016). Natural convection and entropy generation of $\mathrm{Al}_{2} \mathrm{O}_{3}$-water nanofluid in an inclined wavy-wall cavity. International Journal of Heat and Mass Transfer, 97: 511-520. https://doi.org/10.1016/j.ijheatmasstransfer.2016.01.078

[44] Shirvan, K.M., Ellahi, R., Mamourian, M., Moghiman, M. (2017). Effects of wavy surface characteristics on natural convection heat transfer in a cosine corrugated square cavity filled with nanofluid. International Journal of Heat and Mass Transfer, 107: 1110-1118. https://doi.org/10.1016/j.ijheatmasstransfer.2016.11.022

[45] Boulahia, Z., Wakif, A., Sehaqui, R. (2017). Modeling of free convection heat transfer utilizing nanofluid inside a wavy enclosure with a pair of hot and cold cylinders. Frontiers in Heat and Mass Transfer (FHMT). https://doi.org/10.5098/hmt.8.14

[46] Nabavizadeh, S.A., Talebi, S., Sefid, M., Nourmohammadzadeh, M. (2012). Natural convection in a square cavity containing a sinusoidal cylinder. International Journal of Thermal Sciences, 51: 112-120. https://doi.org/10.1016/j.ijthermalsci.2011.08.021

[47] Sheikholeslami, M., Shehzad, S.A., Li, Z., Shafee, A. (2018). Numerical modeling for alumina nanofluid 
magnetohydrodynamic convective heat transfer in a permeable medium using Darcy law. International Journal of Heat and Mass Transfer, 127: 614-622. https://doi.org/10.1016/j.ijheatmasstransfer.2018.07.013

[48] Sheikholeslami, M. (2018). Application of Darcy law for nanofluid flow in a porous cavity under the impact of Lorentz forces. Journal of Molecular Liquids, 266: 495503.https://doi.org/10.1016/j.molliq.2018.06.083

[49] Sheikholeslami, M. (2018). Finite element method for PCM solidification in existence of $\mathrm{CuO}$ nanoparticles. Journal of Molecular Liquids, 265: 347-355. https://doi.org/10.1016/j.molliq.2018.05.132

[50] Alsabery, A.I., Tayebi, T., Chamkha, A.J., Hashim, I. (2018). Effect of rotating solid cylinder on entropy generation and convective heat transfer in a wavy porous cavity heated from below. International Communications in Heat and Mass Transfer, 95: 197-209. https://doi.org/10.1016/j.icheatmasstransfer.2018.05.00 3

[51] Alsabery, A.I., Ismael, M.A., Chamkha, A.J., Hashim, I. (2018). Numerical investigation of mixed convection and entropy generation in a wavy-walled cavity filled with nanofluid and involving a rotating cylinder. Entropy, 20(9): 664. https://doi.org/10.3390/e20090664

[52] Ali, F.H., Hamzah, H.K., Abdulkadhim, A. (2019). Numerical study of mixed convection nanofluid in an annulus enclosure between outer rotating cylinder and inner corrugation cylinder. Heat Transfer-Asian Research, 48(1): https://doi.org/10.1002/htj.21387

[53] Elshehabey, H.M., Raizah, Z., Öztop, H.F., Ahmed, S.E. (2020). MHD natural convective flow of $\mathrm{Fe}_{3} \mathrm{O}_{4}-\mathrm{H}_{2} \mathrm{O}$ ferrofluids in an inclined partial open complex-wavywalls ringed enclosures using non-linear Boussinesq approximation. International Journal of Mechanical Sciences, 170:

105352 https://doi.org/10.1016/j.ijmecsci.2019.105352

[54] Hussain, S.H., Rahomey, M.S. (2019). Comparison of natural convection around a circular cylinder with different geometries of cylinders inside a square enclosure filled with Ag-nanofluid superposed porousnanofluid layers. Journal of Heat Transfer, 141(2): 022501. https://doi.org/10.1115/1.4039642

[55] Mebarek-Oudina, F. (2019). Convective heat transfer of Titania nanofluids of different base fluids in cylindrical annulus with discrete heat source. Heat Transfer-Asian Research, 48(1): https://doi.org/10.1002/htj.21375

[56] Mahanthesh, B., Lorenzini, G., Oudina, F.M., Animasaun, I.L. (2019). Significance of exponential space-and thermal-dependent heat source effects on nanofluid flow due to radially elongated disk with Coriolis and Lorentz forces. Journal of Thermal Analysis and Calorimetry, 2019: 1-8. https://doi.org/10.1007/s10973-019-08985-0

[57] Mebarek-Oudina, F., Bessaïh, R. (2019). Numerical simulation of natural convection heat transfer of copperwater nanofluid in a vertical cylindrical annulus with heat sources. Thermophysics and Aeromechanics, 26(3): 325334. https://doi.org/10.1134/S0869864319030028

[58] Gourari, S., Mebarek-Oudina, F., Hussein, A.K., Kolsi, L., Hassen, W., Younis, O. (2019). Numerical study of natural convection between two coaxial inclined cylinders numerical study of natural convection between two coaxial inclined cylinders. International Journal of Heat and Technology, 37(3): 779-786. https://doi.org/10.18280/ijht.370314

[59] Parveen, R., Mahapatra, T. (2019). Numerical simulation of MHD double diffusive natural convection and entropy generation in a wavy enclosure filled with nanofluid with discrete heating. Heliyon, 5(9): e02496. https://doi.org/10.1016/j.heliyon.2019.e02496

[60] Dogonchi, A.S., Hashemi-Tilehnoee, M., Waqas, M., Seyyedi, S.M., Animasaun, I.L., Ganji, D.D. (2020). The influence of different shapes of nanoparticle on $\mathrm{Cu}-\mathrm{H}_{2} \mathrm{O}$ nanofluids in a partially heated irregular wavy enclosure. Physica A: Statistical Mechanics and its Applications, 540: 123034. https://doi.org/10.1016/j.physa.2019.123034

[61] Al-Zamily, A.M.J. (2017). Analysis of natural convection and entropy generation in a cavity filled with multi-layers of porous medium and nanofluid with a heat generation. International Journal of Heat and Mass Transfer, 106: 1218-1231. https://doi.org/10.1016/j.ijheatmasstransfer.2016.10.102

[62] Ho, C.J., Chen, M., Li, Z. (2008). Numerical simulation of natural convection of nanofluid in a square enclosure: effects due to uncertainties of viscosity and thermal conductivity. International Journal of Heat and Mass Transfer, 51(17-18): 4506-4516. https://doi.org/10.1016/j.ijheatmasstransfer.2007.12.019

[63] Kahveci, K. (2010). Buoyancy driven heat transfer of nanofluids in a tilted enclosure. Journal of Heat Transfer, 132(6): 062501. https://doi.org/10.1115/1.4000744

[64] Abu-Nada, E., Oztop, H.F. (2009). Effects of inclination angle on natural convection in enclosures filled with $\mathrm{Cu}-$ water nanofluid. International Journal of Heat and Fluid Flow, 30(4): 669-678. https://doi.org/10.1016/j.ijheatfluidflow.2009.02.001

[65] Ghasemi, B., Aminossadati, S.M. (2009). Natural convection heat transfer in an inclined enclosure filled with a water-CuO nanofluid. Numerical Heat Transfer, Part A: Applications, 55(8): 807-823. https://doi.org/10.1080/10407780902864623

[66] Oztop, H.F., Mobedi, M., Abu-Nada, E., Pop, I. (2012). A heatline analysis of natural convection in a square inclined enclosure filled with a $\mathrm{CuO}$ nanofluid under non-uniform wall heating condition. International Journal of Heat and Mass Transfer, 55(19-20): 50765086.

https://doi.org/10.1016/j.ijheatmasstransfer.2012.05.007

[67] Basak, T., Chamkha, A.J. (2012). Heatline analysis on natural convection for nanofluids confined within square cavities with various thermal boundary conditions. International Journal of Heat and Mass Transfer, 55(2122): $5526-5543$. https://doi.org/10.1016/j.ijheatmasstransfer.2012.05.025

[68] Bouhalleb, M., Abbassi, H. (2014). Natural convection of nanofluids in enclosures with low aspect ratios. International Journal of Hydrogen Energy, 39(27): $15275-15286$.

https://doi.org/10.1016/j.ijhydene.2014.04.069

[69] Mansour, M., Bakier, M. (2013). Free convection heat transfer in complex-wavy-wall enclosed cavity filled with nanofluid. International Communications in Heat and Mass Transfer, 44: 108-115. https://doi.org/10.1016/j.icheatmasstransfer.2013.02.01 5 
[70] Hussein, A.K., Hussain, S.H. (2016). Heatline visualization of natural convection heat transfer in an inclined wavy cavities filled with nanofluids and subjected to a discrete isoflux heating from its left sidewall. Alexandria Engineering Journal, 55(1): 169186. https://doi.org/10.1016/j.aej.2015.12.014

[71] Alsabery, A.I., Saleh, H., Hashim, I., Hussain, S.H. (2016). Darcian natural convection in inclined square cavity partially filled between the Central square hole filled with a fluid and inside a square porous cavity filled with nanofluid. Journal of Applied Fluid Mechanics, 9(4): 1763-1775. https://doi.org/10.18869/acadpub.jafm.68.235.24575

[72] Rashed, Z.Z., Ahmed, S.E., Aly, A.M. (2019). Heat transfer enhancement in the complex geometries filled with porous media. Thermal Science, 166-166. https://doi.org/10.2298/TSCI181218166R

[73] Chamkha, A.J., Ismael, M.A. (2014). Natural convection in differentially heated partially porous layered cavities filled with a nanofluid. Numerical Heat Transfer, Part A: Applications, 65(11): 1089-1113 https://doi.org/10.1080/10407782.2013.851560

\section{NOMENCLATURE}

B Magnetic field

$\mathrm{C}_{\mathrm{p}} \quad$ Specific heat at constant pressure (kJ/kg.K)

g Gravitational acceleration $\left(\mathrm{m} / \mathrm{s}^{2}\right)$

$\mathrm{k} \quad$ Thermal conductivity (W/m.K)

P Dimensionless pressure

Pr Prandtl number $\left(v_{\mathrm{f}} / \alpha_{\mathrm{f}}\right)$

$\mathrm{R} \quad$ Radius differences of inner and outer cylinder

R cavity $(\mathrm{m})$

$\mathrm{R}_{\mathrm{o}} \quad$ Base circle $(\mathrm{m})$

$\mathrm{Ra} \quad$ Rayleigh number $\left(\mathrm{g} \beta_{\mathrm{f}} \mathrm{L}^{3} \Delta \mathrm{T} / \nu_{\mathrm{f}} \alpha_{\mathrm{f}}\right)$
T Temperature $(\mathrm{K})$

$\mathrm{T}_{\mathrm{c}} \quad$ Temperature of the cold surface $(\mathrm{K})$

$\mathrm{T}_{\mathrm{h}} \quad$ Temperature of the hot surface $(\mathrm{K})$

q Heat coefficient

$\mathrm{Nu}$ Average Nusselt number hot inner circular cylinder

$\mathrm{U}$ Dimensionless velocity component in $\mathrm{x}$-direction

$\mathrm{u} \quad$ Velocity component in $\mathrm{X}$-direction $(\mathrm{m} / \mathrm{s})$

$\mathrm{V}$ Dimensionless velocity component in y-direction

v Velocity component in y-direction $(\mathrm{m} / \mathrm{s})$

$\mathrm{X}$ Dimensionless coordinate in horizontal direction

$\mathrm{x}$ Cartesian coordinates in horizontal direction (m)

Y Dimensionless coordinate in vertical direction

y Cartesian coordinate in vertical direction (m)

\section{Greek symbols}

$\alpha \quad$ Thermal diffusivity $\left(\mathrm{m}^{2} / \mathrm{s}\right)$

$\theta \quad$ Dimensionless temperature $(\mathrm{T}-\mathrm{Tc} / \Delta \mathrm{T})$

$\Psi \quad$ Dimensional stream function $\left(\mathrm{m}^{2} / \mathrm{s}\right)$

$\Phi \quad$ Nanofluid volume fraction

$\psi \quad$ Dimensionless stream function

Gr Grashof number

$\mu \quad$ Dynamic viscosity $(\mathrm{kg} / \mathrm{m} . \mathrm{s})$

$v \quad$ Kinematic viscosity $\left(\mathrm{m}^{2} \mathrm{~s}^{-1}\right)$

$\beta \quad$ Volumetric coefficient of thermal expansion $\left(\mathrm{K}^{-1}\right)$

P Density $\left(\mathrm{kg} / \mathrm{m}^{3}\right)$

$\delta \quad$ Inner cylinder position

\section{Subscripts}

c Cold

f $\quad$ Fluid (pure)

h hot 